Article

\title{
Carbon Nanotubes: Solution for the Therapeutic Delivery of siRNA?
}

\section{Lynn Kirkpatrick ${ }^{1, *}$, Michelle Weiss ${ }^{1}$, Anton Naumov ${ }^{1}$, Geoffrey Bartholomeusz ${ }^{2}$, R. Bruce Weisman ${ }^{3}$ and Olga Gliko ${ }^{1}$}

1 Ensysce Biosciences Inc., 7000 Fannin St., Suite 2115, Houston, TX 77030, USA;

E-Mails: mweiss@ensysce.com (M.W.); anaumov@ensysce.com (A.N.); ogliko@ensysce.com (O.G.)

2 MD Anderson Cancer Center, 1901 East Road, Unit 1950, Houston, TX 77054, USA; E-Mail: gbarthol@mdanderson.org

3 Department of Chemistry, Rice University, 6100 Main Street, Houston, TX 77005, USA; E-Mail:weissman@rice.edu

* Author to whom correspondence should be addressed; E-Mail: 1kirkpatrick@ensysce.com; Tel.: +1-713-790-0080; Fax: +1-713-790-0091.

Received: 1 December 2011; in revised form: 2 February 2012 / Accepted: 6 February 2012 / Published: 13 February 2012

\begin{abstract}
Carbon nanotubes have many unique physical and chemical properties that are being widely explored for potential applications in biomedicine especially as transporters of drugs, proteins, DNA and RNA into cells. Specifically, single-walled carbon nanotubes (SWCNT) have been shown to deliver siRNA to tumors in vivo. The low toxicity, the excellent membrane penetration ability, the protection afforded against blood breakdown of the siRNA payload and the good biological activity seen in vivo suggests that SWCNT may become universal transfection vehicles for siRNA and other RNAs for therapeutic applications. This paper will introduce a short review of a number of therapeutic applications for carbon nanotubes and provide recent data suggesting SWCNT are an excellent option for the delivery of siRNA clinically.
\end{abstract}

Keywords: single-walled carbon nanotube; short interfering RNA; therapeutic delivery 


\section{Introduction}

Carbon nanotubes (CNT) have many unique physical and chemical properties that are being widely explored for potential applications in biomedicine including drug delivery systems (DDS), sensors, imaging agents and composites [1-6]. The high surface area, conductivity, high tensile strength, typical high aspect ratios as well as potentially greater adsorption abilities due to their cylindrical structure make them a novel nanomaterial for drug delivery and biomedical applications [7].

Carbon nanotubes as molecular transporters can shuttle various types of biological molecules, including drugs [1], proteins [6], DNA [8] and RNA [9] into cells. The main limitations of delivery for many therapeutic agents include poor solubility, rapid deactivation, toxicity, unfavorable pharmacokinetics (PK) and poor biodistribution. For these purposes it is important to also consider the inseparable relationship between the solubility, PK and bioavailability and toxicity of the DDS being considered. Since early 2000 carbon nanotubes have been explored as DDS and most findings suggest that they can be used safely, they protect their cargo, their PK and biodistribution can be altered to achieve localization and effective biological activity can be achieved [7,10,11].

Carbon nanotubes are a family of highly elongated tubular nanostructures composed of sp2-hybridized carbon atoms covalently bonded into six-membered rings. The nanotubes exist in a variety of well-defined structural forms [7]. Single walled carbon nanotubes (SWCNT) or multiwalled carbon nanotubes (MWCNT) have been each explored for biological utility. Advantages of using SWCNT are that they have a smaller diameter, are more flexible and offer additional photoluminescence that has been exploited for imaging. MWCNT present a wider surface area for payload functionalization and may allow more efficient internal encapsulation. The material shows physiochemical properties which are dependent on size, chemical composition, surface structure, solubility, shape and aggregation. These parameters can modify cellular uptake, protein binding, translocation and toxicity. The lack of any consistent fabrication of CNT with structurally and chemically controlled processes unfortunately limits the ability to compare the literature with respect to many of the studies that have reported on this DDS.

\subsection{Therapeutic Uses of Carbon Nanotubes}

Therapeutic uses of CNT have been expanded over the last decade as the properties of the CNT have become more fully appreciated. Therapeutics with limitations such as poor solubility, rapid deactivation and unfavorable PK resulting in limited biodistribution require DDS and the use of CNT to overcome these issues has been explored by numerous laboratories [1-3,6,8,9,12-16]. Therapeutic delivery of chemotherapeutic agents using SWCNT have reported reduced toxicity [3], greater biological activity [1], targeting ability [17,18] and controlled release [19]. Reports have also shown that both SWCNT and MWCNT have utility for the delivery of oligonucleotides [8,12-15]. Not only do CNT carry the oligo payload into cells, they provide a protection from degradation while in the circulation [20]. Additionally, the intrinsic fluorescence of SWCNT in the NIR region provides an opportunity for imaging when these are used as a delivery vehicle [4,5,21-23]. SWCNT have been developed into sensing devices for human disease including for the detection of lung cancer and kidney disease in human breath, glucose levels in diabetics and $\mathrm{H}_{2} \mathrm{O}_{2}$ in reactive oxygen signaling 
pathways [24-27]. CNT arrays have also been used to explore delivery of recombinant human bone morphogenetic protein-2 as potential implanted CNT-based materials for gene and protein based delivery [6]. Local exposure of tumors containing SWCNT to NIR light has been found to provide excellent photothermal ablation [27-30].

\subsection{Toxicity}

Pristine CNT lack solubility [31], have a tendency for the formation of thick and inhomogeneous bundles, have short circulation half-lives, bio-incompatibility and immunogenicity. There have been studies that have examined pristine (non-functionalized) CNT for pulmonary toxicity [32,33], intratracheal instillation [34,35], pharyngeal aspiration [36], skin exposure [37] and following subcutaneous administration [38,39]. These studies reported acute pulmonary toxicity, induction of granulomas and inflammatory reactions to the pristine CNT. The length of the tubes factors in on toxicity with shorter material more readily excreted and handled through the tissues [40,41]. Other studies using functionalized CNT reported no inflammatory response with subcutaneous administration [39] and found them to be well tolerated following i.v. administration over an extended period of time [1,40-42]. Hence, CNT need some type of functionalization, whether covalently or non-covalently associated with the surface for solubility and biocompatibility. This functionalization allows the preparation of soluble, well dispersed CNT samples and improves their toxicological profile. It has been found that there is an inverse correlation between toxicity and the extent of CNT functionalization.

Complement activation of CNT has been explored in vitro using a number of SWCNT and double-walled carbon nanotube (DWCNT) samples [43] and with long circulating PEGylated SWCNT [44]. In their study, Salvador-Morales et al. [43] oxidized their samples and coated with $0.5 \%$ Triton X-100 but did not indicate the median length of the nanotubes in the sample. They also reported an inability to centrifuge or filter their samples of CNT as they were hard to resuspend which suggests that the nanotubes were not well functionalized with the coating. The conclusions were that both SWCNT and DWCNT activate the human serum complement system and the DWCNT also activate the alternative pathway but they suggest that altering the surface chemistry may diminish or eliminate these effects. In an attempt to address this, Hamad et al. explored more fully the complement activation with PEGylated SWCNT samples. In this study they used amino-poly(ethylene glycol) 5000- $^{-}$ (1,2-distearoyl-sn-glycer-3-phophoethanolamine (amino-PEG 5000 -DSPE) or methoxy (MEO)-PEG ${ }_{5000^{-}}$ DSPE to coat SWCNT. The excess PEG-conjugates were removed from the samples by filtration and the lengths were estimated by atomic force microscopy (AFM) to range from 50 to $300 \mathrm{~nm}$. Human serum complement activation was observed in vitro, however more inconclusive results were noted in vivo using a rat model. Again it was speculated that inadequate surface protection in the samples may account for these findings.

The heterogeneity of the samples being used in studies of toxicity of CNT (SWCNT, MWCNT, non-functionalized, functionalized, micron length samples, nm length samples, pristine unpurified, purified to remove bundles and contaminating metals, well dispersed or aggregated) does not allow a single conclusion to be drawn as to the toxicity of this potential DDS $[40,45,46]$. There are however a number of positive observations made with carefully prepared CNT solutions that have been used in 
biological applications [46-49]. Significantly, a number of studies found that well functionalized carbon nanotubes are stable in physiological environments and can be used with little to no toxicity in vitro [46] and in vivo in mice models [47,49]. Endpoints such as survival and clinical laboratory parameters reveal no evidence of toxicity over 4 months with the i.v. administration of well dispersed SWCNT complexes to mice despite the persistence of the functionalized SWCNT in liver and spleen for the 4 month period [49].

\subsection{PK and Biodistribution}

As with toxicity, the biodistribution and elimination of CNT depends on the surface chemistry of the SWCNT. Not only does this include the size and degree of functionalization of the CNT [41,47], it also can be altered by the length and degree of branching of functionalization entities such as polyethyleneglycol (PEG) $[39,42]$. Studies have shown that tissue accumulation is proportional to degree and type of functionalization and excretion route is dependent on size [40]. Chuerukuri et al. [50] reported a half-life $\left(\mathrm{t}_{1 / 2}\right)$ of approximately $1 \mathrm{~h}$ following the delivery to a rabbit of SWCNT funcitionalized with Pluronic F108. Singh et al. [48] reported that SWCNT functionalized with dietheylentriaminepentaacetic (DTPA) and labeled with indium $\left({ }^{111} \mathrm{In}\right)$ were not retained in any of the reticuloendothelial system (RES) organs and were rapidly cleared for systemic blood circulation by renal excretion. In this study the product was measured to have a $3 \mathrm{~h} \mathrm{t}_{1 / 2}$. Lui et al. [42] examined the length and branching of PEG phospholipid analogues used for functionalization of SWCNT samples that were $100 \pm 50 \mathrm{~nm}$ and determined circulation times were significantly altered from $\sim 1 \mathrm{~h}$ with SWCNT functionalized with linear (l-)2K PEG to $15 \mathrm{~h}$ with branched (br-)7K PEG. The $b r-7 \mathrm{~K}$ PEG functionalized SWCNT demonstrated relatively low uptake in the RES and near complete clearance from the main organs in approximately 2 months. The distribution of the various samples showed similar organ distribution but the $b r-7 \mathrm{~K}$ PEG/SWCNT showed 50\% less liver accumulation on day 1 than the l-2K PEG/SWCNT sample. Besides liver and spleen accumulation on day 1, there was found slightly more than $1 \% \mathrm{ID} / \mathrm{g}$ tissue in bone, kidney and intestine. There was an appreciable amount of SWCNT in feces at $8 \mathrm{~h}$ post injection (pi) and a small amount in bladder and kidney at $24 \mathrm{~h}$ pi providing evidence for biliary excretion as well as renal excretion to a lesser extent. Necropsy, histology and blood chemistry performed at 3 mo pi indicated no toxicity and there was no loss of body weight in any of the mice. They concluded that SWCNT preparations with a blood circulation half-life of $12-13 \mathrm{~h}$ show relatively low RES and skin accumulation together with high tumor uptake, ideal for potential cancer treatment applications.

Ruggiero et al. [41] examined the PK of SWCNT (mean length of $195 \pm 69 \mathrm{~nm}$; range up to $500 \mathrm{~nm}$; $\zeta$-potential of $-8.9 \pm 3.3 \mathrm{mV}$ ) covalently functionalized with amino groups to which were appended two fluorescent dyes [Alexa Fluor (AF)488 and AF680] and metal-ion cheland DOTA radiolabeled

with ${ }^{86} \mathrm{Y}$. Use of multimodal imaging determined that the constructs were rapidly renally cleared intact by glomerular filtration with partial tubular reabsorption and transient translocation into the proximal tubular cell nuclei. Although the constructs were 10 to 20 times the 30 to $50 \mathrm{kDa}$ cut-off for glomerular filtration, it was speculated that the high aspect ratio of these large entities (100:1 to 500:1) were the reason why they were cleared similarly to small molecules. 
The above studies contrast those conducted by Yang et al. [51] who administered pristine tubes non-functionalized and suspended only in 1\% tween. Yang found that in contrast to the findings with modified/functionalized CNT, the excretion of the non-functionalized SWCNT was very limited over 28 days. Additionally, the distribution pattern was altered in that the SWCNT distributed internally mainly to lung on a per gram basis as well as to the liver and spleen. It was also found that there was CNT found in the brain therefore supporting the possibility of using this platform to deliver agents through the blood brain barrier. It is interesting to note that over the 28 day period of the study there was little excretion of the SWCNT and yet none of the animals exhibited any clinical sign of abnormality from as much as a $2 \mathrm{mg}$ dose. This data again supports the necessity for delivery of functionalized CNT to mask the hydrophobicity of the SWCNT and to ensure not only adequate biodistribution to desired tissues but also a reasonable clearance rate through biliary or renal routes.

\subsection{SWCNT Delivery of siRNA}

It appears from the emerging data that SWCNT, when properly solubilized and functionalized, can effectively and safely shuttle biomolecules into cells. Our laboratory has been exploring the use of carbon nanotubes as a universal DDS for siRNA and other oligonucleotides. Therapeutic applications of oligonucleotide payloads have also been explored by others using siRNA covalently linked to functionalized SWCNT, covalently linked siRNA to tethering molecules on SWCNT, and on chemically functionalized MWCNT [12-16]. siRNA:SWCNT+ functionalized complexes targeting CD80 and SOCS1 were shown to be effective in vitro and in vivo following systemic delivery [12]. Thiol-modified siRNA have been linked to the amine-terminated polyethylene glycol phospholipids on the sidewalls of SWCNT through cleavable disulfide bonds (SWCNT-(PL-PEG2000)-SS-siRNA). Results revealed that cellular uptake of SWCNT complex and dependent on the polyethylene glycol (PEG) chain length $[13,14]$. The study using MWCNT contrasted studies with SWCNT in that the diameter and length of the nanotubes were much larger (lengths of up to $2 \mu \mathrm{m}$ and diameters of $20-30 \mathrm{~nm}$ ) $[15,16]$. One study using stereotactic administration of the complexes into brains of mice and rats reported a therapeutic benefit [16].

Our SWCNT delivery of siRNA utilizes non-covalent complexation of HiPCO SWCNT in formulations that are stable and biocompatible. The SWCNT solutions are processed to provide median lengths of 300-400 $\mathrm{nm}$ with various components that produce circulation times ranging from minutes to hours. The complexes have been delivered systemically to animals with and without subcutaneous human tumor xenografts. The endpoints that have been observed include pharmacokinetics, toxicity, antitumor activity and target protein knockdown (KD). We have produced stable formulations with siRNA targeted to PLK1, Trx-1, HIF-1 $\alpha$, K-RAS, EGFR as well as a number of scrambled sequences [9]. The biological activity and protein target $\mathrm{KD}$ have been evaluated in a number of cell lines including MiaPaCa-2 human pancreatic carcinoma, H2122 human non-small cell lung cancer, MCF7 human breast cancer, MDA-MB-231 human breast cancer and RGM1 normal gastric mucosa. The advantages of using SWCNT to deliver siRNA include providing resistance to nuclease digestion, the stability of the complex in the presence of serum, efficient transfection reducing the amount of siRNA required for systemic delivery to produce tumor target KD and the lack of toxicity of the complex and the nanotube carrier. 
In this report we present studies using optimized SWCNT solutions with consistent siRNA compositions and physical properties including size and state of dispersion. The in vitro data demonstrate that the siRNA/SWCNT solutions are stable in biological fluid, enter cells and release siRNA intracellularly. In vivo it has been found that the pharmacokinetic $t_{1 / 2}$ of the siRNA/SWCNT can be modified through excipient content of the complexes. Most importantly, systemic delivery of the complexes in vivo has produced antitumor activity with tumor target knockdown with an apparent lack of toxicity. We believe based on our work and that of others that the excellent membrane penetration ability, the low toxicity, the protection afforded siRNA against breakdown in blood and the favorable biological activity seen in vivo will allow SWCNT to become universal transfection vehicles for siRNA and other RNAs for therapeutic applications.

\section{Results and Discussion}

\subsection{Processing of SWCNT Samples for Biological Evaluation}

The preparation of well functionalized SWCNT with siRNA has been explored using a number of variables including siRNA concentration and composition, vehicle composition, temperature, sonication time and power, Scheme 1. When different siRNA or miRNA solutions have been used as functionalizing agents there have been no differences in the preparation quality as determined by NIR and absorbance spectra measured with NS2 Nanospectralyzer (data not shown). The stability of siRNA/SWCNT samples prepared with and without filtration to remove excess siRNA from the solution was evaluated at $4{ }^{\circ} \mathrm{C}$ and room temperature. It was found that the SWCNT concentration in solution did not change over a 1 month period at either temperature. This indicated that there was still sufficient complexation by siRNA to solubilize the SWCNT. To determine whether any siRNA had dissociated from the SWCNT, the solutions were refiltered at a 1 week time point and the filtrate analyzed for siRNA using Nanodrop spectrophotometer. No siRNA was detected in solution (data not shown). This demonstrates that the solutions can be prepared and filtered to retain the uncomplexed siRNA, washed and resuspended to a desired SWCNT concentration and stored for a reasonable period of time without loss of siRNA from the SWCNT.

Scheme 1. Preparation of siRNA/SWCNT or siRNA/PEG/SWCNT complexes.

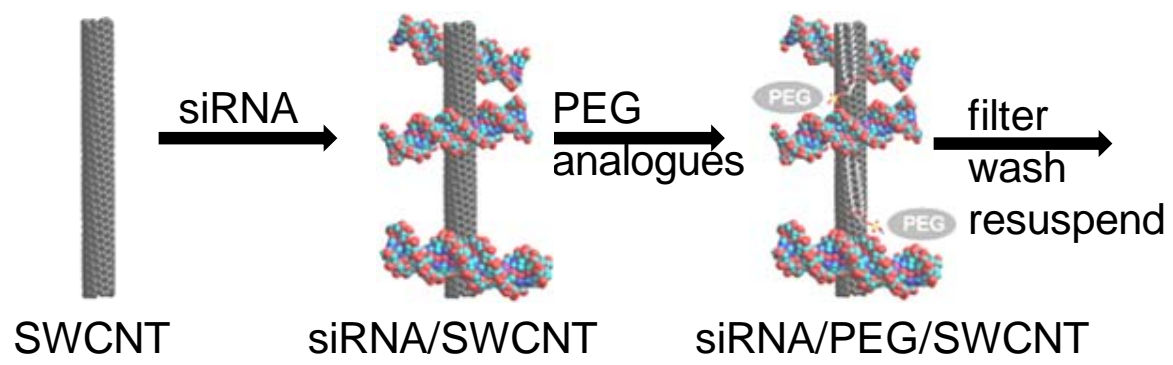

Investigation into sonication time showed a negative correlation with SWCNT length distribution (Figure 1a) with little change found following approximately $8 \mathrm{~min}$ of processing (not shown). In order to ensure maximum complexation of siRNA to SWCNT, sonication of siRNA and SWCNT is 
undertaken prior to the addition of other excipients, providing coverage of the SWCNT to approximately a $20 \% \mathrm{w} / \mathrm{w}$ ratio of siRNA to SWCNT.

Analyses of the SWCNT in the samples by AFM provided an ability to determine the length distribution and coating of payload. Dynamic light scattering (DLS) was also used to determine length with the anticipation of it providing a less labor intensive method of length analyses. The samples analyzed were composed of a number of siRNA functionalizations and excipient compositions. The mean lengths as determined by DLS consistently of siRNA/l-PEG/SWCNT provided an over estimation of the SWCNT length of approximately 1.25 to 1.5 greater than that determined by AFM, while the overestimation of length of SWCNT processed using the br-PEG had the largest discrepancies of $\sim 2.3$ times greater than that determined by AFM, Figure 1b,c. This confounds the ability to use DLS alone to provide a length distribution of the prepared samples but would allow an estimate to be acquired. The zeta potential of the particles also varied depending on the composition of the coating with $\zeta$-potential of siRNA/SWCNT particles $-23.4 \pm 1.0$, siRNA/l-PEG/SWCNT $-3.0 \pm 1.5$ and siRNA/br-PEG/SWCNT $-6.1 \pm 1.5$.

Figure 1. (a) AFM length analyses of siRNA/SWCNT complexes sonicated for 15 seconds, 1 min or $5 \mathrm{~min}$; (b,c) AFM (red) and DLS (blue) length distribution and means of processed samples of (b) siRNA/l-PEG/SWCNT; (c) siRNA/br-PEG/SWCNT.

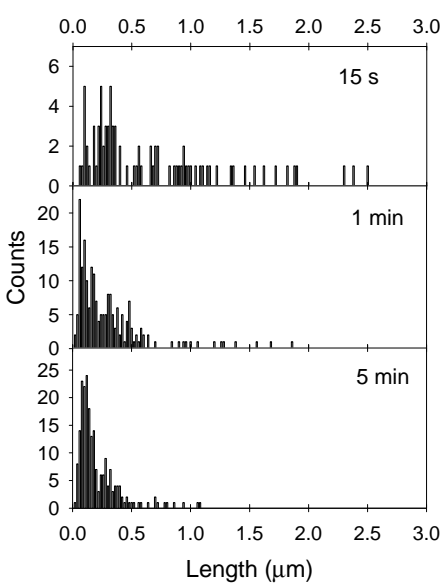

(a)

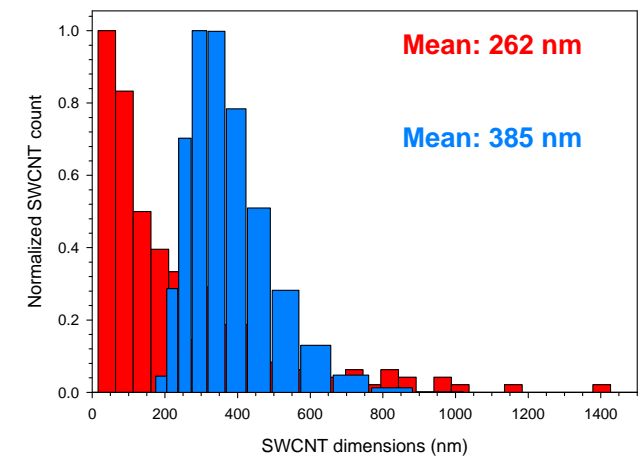

(b)

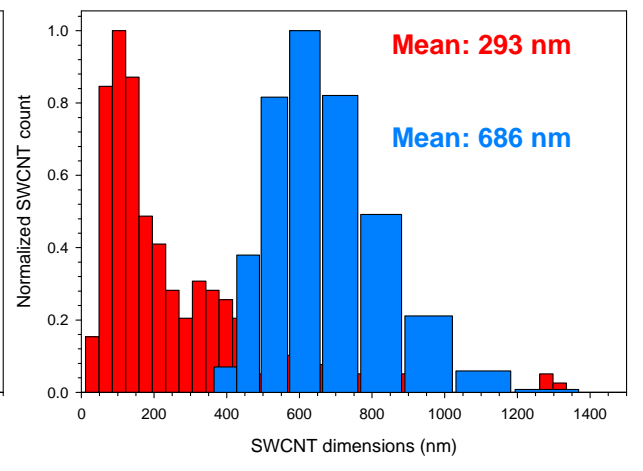

(c)

The AFM analyses of each sample demonstrate that the SWCNT are well functionalized. Figure 2 illustrates compositions of siRNA/SWCNT, siRNA/l-PEG 5000/SWCNT and siRNA/SWCNT complex exposed to bovine serum albumin. These provide evidence that when siRNA/SWCNT complexes are exposed to subsequent excipients including $1 \%$ bovine serum albumin (BSA) for $\sim 4 \mathrm{~h}$, the siRNA is not displaced from the SWCNT, suggesting that in vivo delivery of the siRNA/SWCNT will not result in the loss of the payload in the blood. The AFM images characterize the coating efficiency, differentiating between uncoated regions and those coated by siRNA, PEG and BSA. The diameter measurements identify regions with bare SWCNT having a diameter of $\sim 1 \mathrm{~nm}$, siRNA coated $>1$ to $3 \mathrm{~nm}$, linear or branched PEG 5000 coating $\sim 4$ to $6 \mathrm{~nm}$ and BSA coating areas of $\sim 7$ to $10 \mathrm{~nm}$. The diameters of the siRNA coated regions and the BSA regions correspond to those of computer models of the SWCNT complexes, Figure 3. 
Figure 2. Atomic force microscopy of SWCNT complexed to (a) siRNA; (b) siRNA followed by l-PEG-5000; (c) siRNA followed by exposure to $1 \%$ bovine serum albumin (BSA). Diameters: SWCNT $\sim 1 \mathrm{~nm}$; siRNA coated $\sim 1$ to $3 \mathrm{~nm}$; linear $(l)$ or branched (br)-PEG 5000 coating $\sim 4$ to $6 \mathrm{~nm}$; BSA $\sim 7$ to $10 \mathrm{~nm}$.

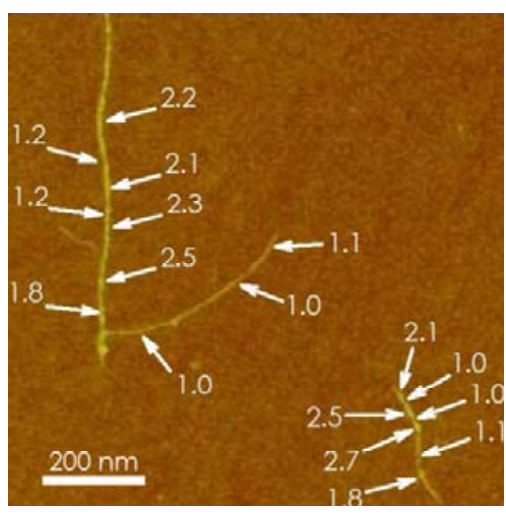

(a)

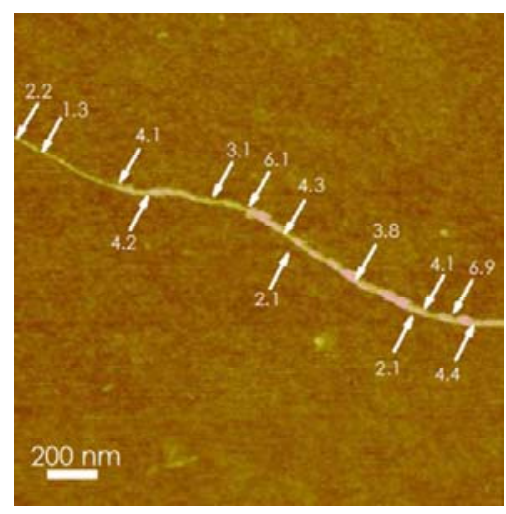

(b)

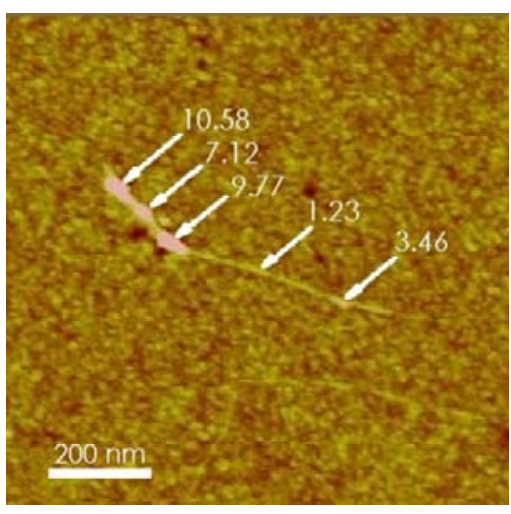

(c)

Figure 3. HyperChem model of (a) siRNA complexed to SWCNT and (b) human serum albumin complexed to SWCNT with diameter distances labeled.

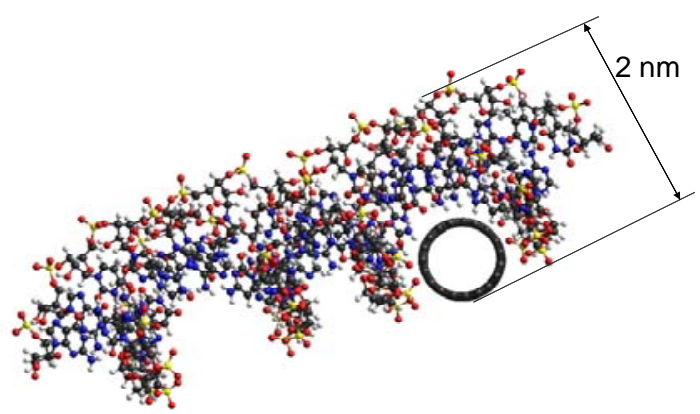

(a)

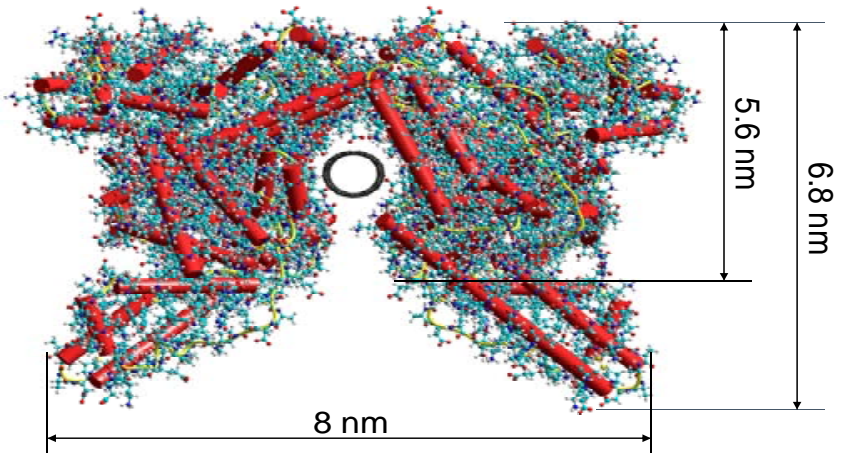

(b)

\subsection{Transfection of siRNA/SWCNT Complexes}

We examined the transfection of samples functionalized with siRNA alone or with different excipients. These soluble siRNA/SWCNT complexes are stable in solution and transfect siRNA in vitro (Figures 4 and 5). It was found that when Cy-3 labeled siRNA was complexed to SWCNT the fluorescence was quenched (Figure 4a). This preparation was used to explore the release of siRNA from the SWCNT when exposed to cells in vitro or administered to animals in vivo with varying complex compositions. Cy-3-siRNA/SWCNT complexes added to either MiaPaCa-2 or H2122 NSCLC cells (data not shown) in culture, entered cells and using NIR fluorescence were observed by $1 \mathrm{~h}$ in cells. At $6 \mathrm{~h}$ post exposure to the siRNA/SWCNT complex, SWCNT were observed inside all cells (Figure 4). The same cells viewed using visible fluorescence to detect the Cy-3 labeled siRNA showed corresponding intracellular fluorescence from the siRNA, suggesting the siRNA had released from SWCNT following its transfection into the cell. It is reported that SWCNT complexes readily penetrate cell membranes by a process described as nanospearing, as tiny needles passing through the 
cell membrane [52], in addition to the typical endocytosis [53]. Using an equivalent amount of siRNA with liposomal delivery to compare to the SWCNT delivery revealed that at $1 \mathrm{~h}$ the liposomal Cy-3-siRNA remained concentrated in focused areas of the cytoplasm in contrast to SWCNT delivery which appeared to allow rapid intracellular dispersion of the siRNA (Figure 5).

Figure 4. (a) Cy-3-siRNA complexed to SWCNT is not fluorescent (lane 3); (b) H2122 NSCLC cells in culture exposed to Cy-3-siRNA/SWCNT $1 \mu \mathrm{g} / \mathrm{mL}$ for $6 \mathrm{~h}$. Cells were washed and examined by bright field and fluorescent microscopy. Top views illustrate left: the $\mathrm{H} 2122$ cells in culture $(10.6 \mathrm{pix} / \mu \mathrm{m})$; right: intracellular Cy-3-siRNA by visible fluorescence $(10.6 \mathrm{pix} / \mu \mathrm{m})$; and bottom views left: illustrate the same H2122 cells in culture ( 2 pix $/ \mu \mathrm{m})$; right: the intracellular SWCNT by NIR fluorescence $(2 \mathrm{pix} / \mu \mathrm{m})$ in the same cells. All cells in culture contained both the siRNA and SWCNT. Control cells not exposed to Cy-3 siRNA/SWCNT complex showed no fluorescence under either condition (data not shown).

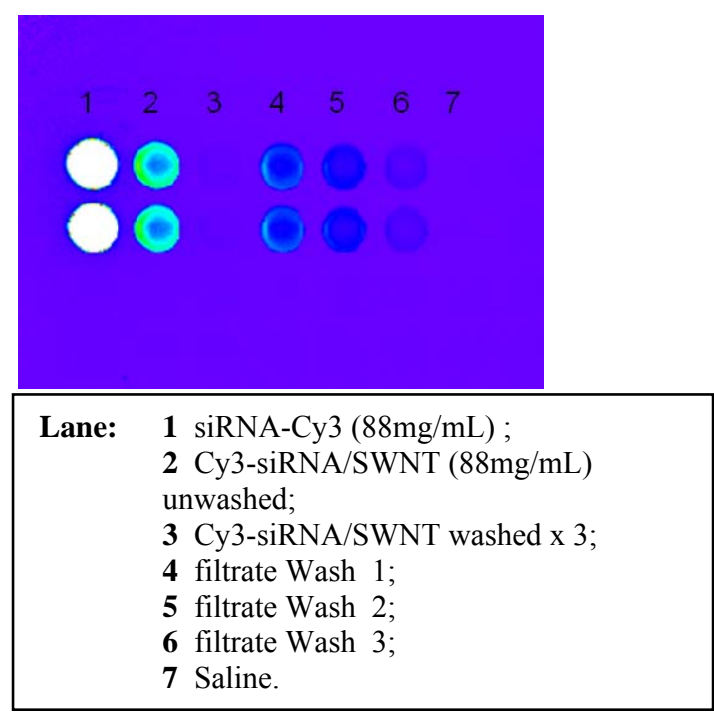

(a)

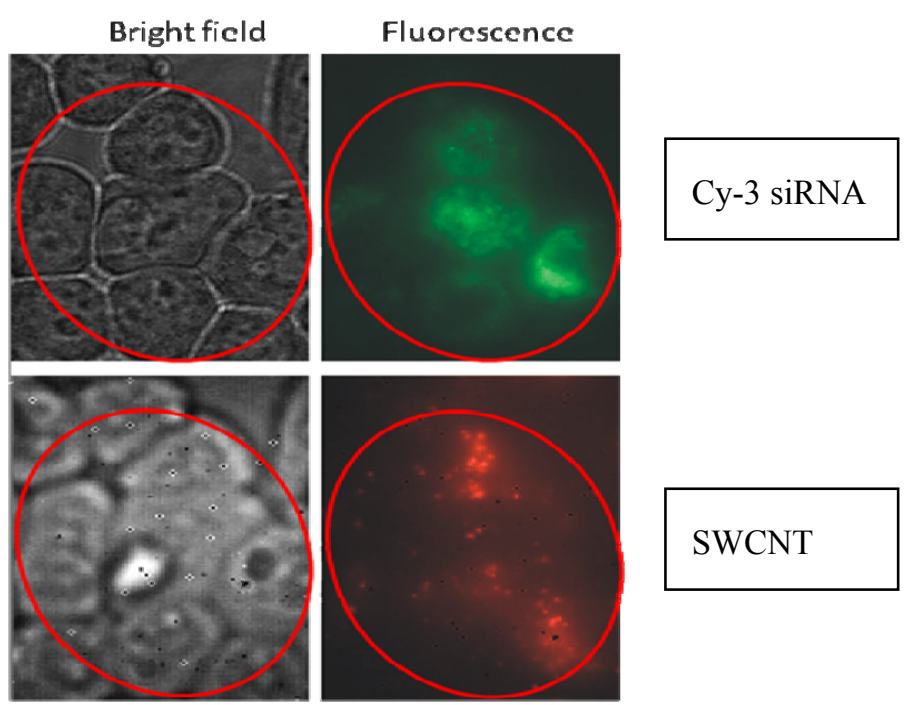

(b)

Figure 5. MiaCaPa-2 cells exposed to: (a) Cy-3-siRNA/SWCNT for $1 \mathrm{~h}$. SWCNT NIR fluorescence in red and Cy-3-siRNA fluorescence in green showing siRNA distribution throughout the cells; (b) Cy-3-siRNA using liposomal delivery for $1 \mathrm{~h}$ with same amount siRNA as in (a). Green fluorescence showing the focused lipid delivery of siRNA at $1 \mathrm{~h}$.
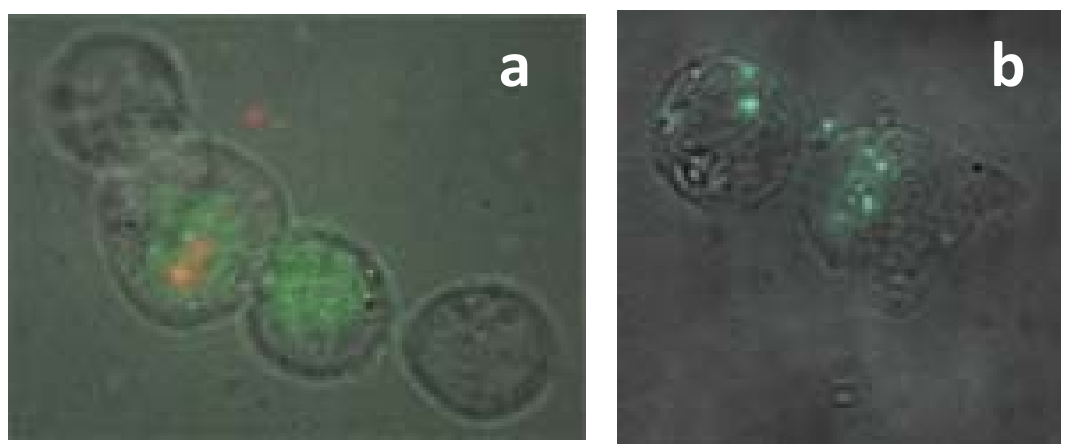


\subsection{Stability of siRNA/SWCNT Complexes}

The advantages of using SWCNT to deliver siRNA include resistance to nuclease digestion, sequence-independent binding, the stability of the complex in the presence of serum, efficient transfection reducing amount of siRNA required for systemic delivery to produce tumor target knockdown (KD). We have examined the siRNA remaining from solutions of siRNA in aqueous PEG versus the same solution complexed with SWCNT when exposed to ribonuclease at $37{ }^{\circ} \mathrm{C}$ for times up to $3 \mathrm{~h}$. Figure 6 shows that within $1 \mathrm{~h}$ the free siRNA was totally digested with less than $0.03 \%$ remaining at $1 \mathrm{~h}$ while approximately $80 \%$ of siRNA complexed to SWCNT remained in solution at 1 and $2 \mathrm{~h}$ and $70 \%$ after $3 \mathrm{~h}$ under same conditions.

Figure 6. siRNA remaining after exposure to ribonuclease (10 units RNAseONE ${ }^{\mathrm{TM}}$ Ribonuclease) at $37{ }^{\circ} \mathrm{C}$ for 1,2 and $3 \mathrm{~h}$ in solutions of free siRNA in $64 \mu \mathrm{M}$ PEG or siRNA complexed to SWCNT with $64 \mu \mathrm{M}$ PEG. No treatment (NT) controls were incubated at $37{ }^{\circ} \mathrm{C}$ for $3 \mathrm{~h}$. Resulting solutions were separated on agarose gels and the siRNA quantified using CareStream In Vivo MS FX PRO imager.

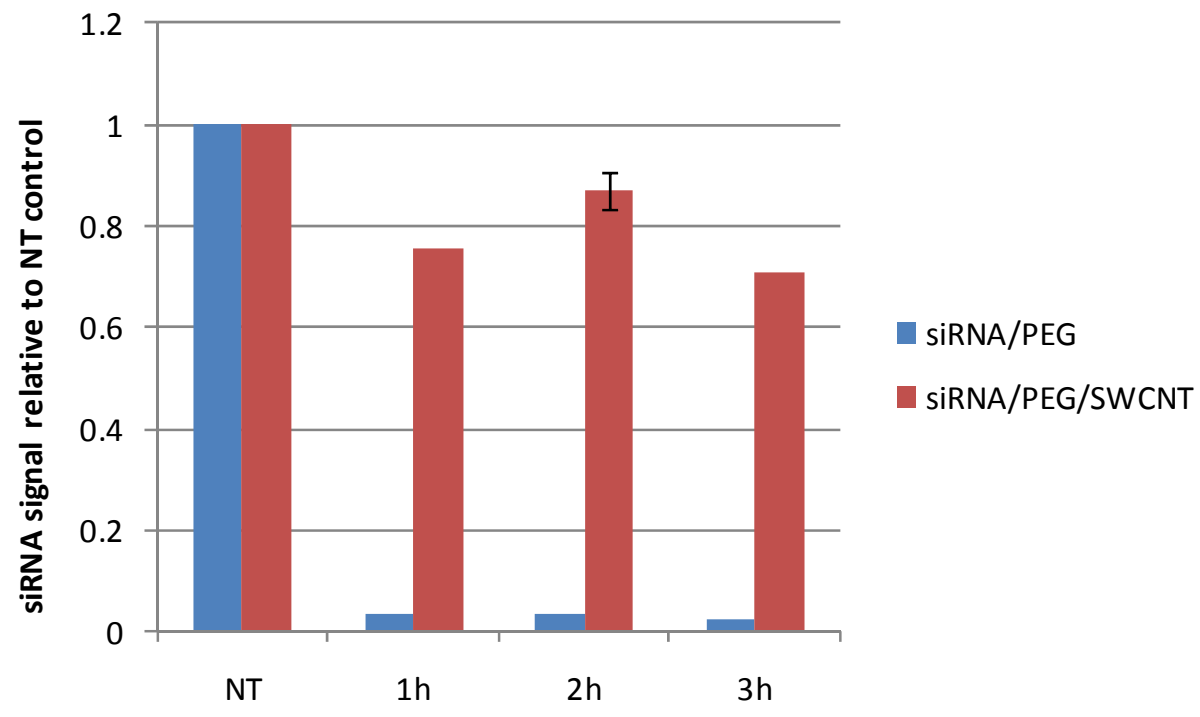

\subsection{Biological Activity}

These soluble siRNA/SWCNT complexes form stable solutions that transfect siRNA in vitro (Figures 4, and 7a) and in vivo (Figures 7b,c and 8) and show time dependent target protein KD. MiaPaCa-2 cells in culture were exposed to siTrx/SWCNT for various times up to $24 \mathrm{~h}$ when media was replaced by fresh and cells were Western blotted at $72 \mathrm{~h}$. Figure $7 \mathrm{a}$ demonstrates that biological activity (target KD) began by $1 \mathrm{~h}$ and increased with further exposure to the $24 \mathrm{~h}$ time point. Target $\mathrm{KD}$ was also measured in vivo (Figure $7 \mathrm{~b}$ ) when mice with large MiaPaCa-2 subcutaneous tumors in flank were treated by i.v. administration siTrx/PEG/SWCNT, sacrificed at 24, 48 and $72 \mathrm{~h}$ and tumor excised and Western blotted. Target protein, Trx KD was observed at $48 \mathrm{~h}$ increasing at $72 \mathrm{~h}$. In a separate study, mice with MiaPaCa-2 tumors were treated with siEGFR/SWCNT or the dual payload siEGFR/siKRAS/SWCNT (Figure 7c). Tumors were excised at $96 \mathrm{~h}$ after i.v. administration and Western blotted for EGFR and KRAS. The target proteins were reduced in each instance where EGFR 
had KD in tumors of mice treated with the siEGFR/SWCNT complex and both EGFR and KRAS target protein were decreased in mice treated with the dual payload siEGFR/siKRAS/SWCNT. In addition to measuring target KD in tumors, SWCNT presence was visualized in tumor tissue slices (Figure 7d) using NIR fluorescence microscopy. The tumor content of SWCNT depend significantly on the pharmacokinetics of the SWCNT preparation, with tumors of animals treated with preparations having $\mathrm{t}_{1 / 2}$ of $10 \mathrm{~min}$ having $1-4$ SWCNT per $150 \times 125 \mu \mathrm{m}$ while that with $\mathrm{t}_{1 / 2}$ of $25 \mathrm{~h}$ having an average of 14 SWCNT per $150 \times 125 \mu \mathrm{m}$ area at $24 \mathrm{~h}$ increasing to an average of 62 SWCNT per $150 \times 125 \mu \mathrm{m}$ area over a $96 \mathrm{~h}$ period.

Figure 7. siRNA/SWCNT complexes produce time dependent target knockdown in vitro and in vivo. (a) MiaPaCa-2 cells in vitro with $10 \%$ FCS were exposed to $\operatorname{siTrx}(13 \mathrm{nM}) / \mathrm{SWCNT}$ at times shown with Western blotting performed at $72 \mathrm{~h}$. Control well: siTrx without SWCNT; (b) siTrx/PEG13 $\mu \mathrm{M} / \mathrm{SWCNT}$ (39 $\mu \mathrm{g}$ SWCNT, $\sim 0.8 \mathrm{mg} / \mathrm{kg}$ siRNA) was injected into tail vein of mice bearing large MiaPaCa-2 tumors. Mice were sacrificed at 24, 48 and $72 \mathrm{~h}$, tumors excised and Western blotted; (c) MiaPaCa-2 tumors from mice treated weekly for 4 weeks with $35 \mu \mathrm{g}$ SWCNT carrying single siEGFR or dual payload siEGFR+siKRAS (0.8 mg/kg siRNA) (Figure $8(\mathrm{~A})$ ), excised and Western blotted $96 \mathrm{~h}$ following 4th treatment; (d) NIR microscopy of SWCNT in tumor slice at $24 \mathrm{~h}$. Arrows identify SWCNT in tumor with corresponding characteristic NIR spectra used to distinguish SWCNT from biological fluorescing features.

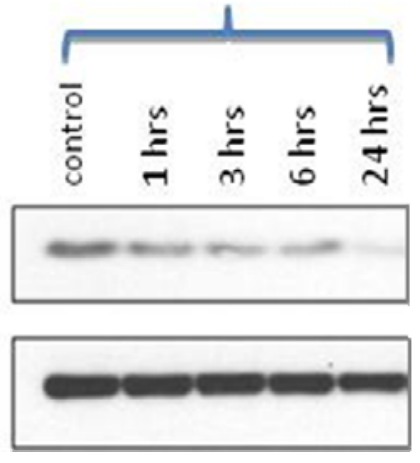

(a)

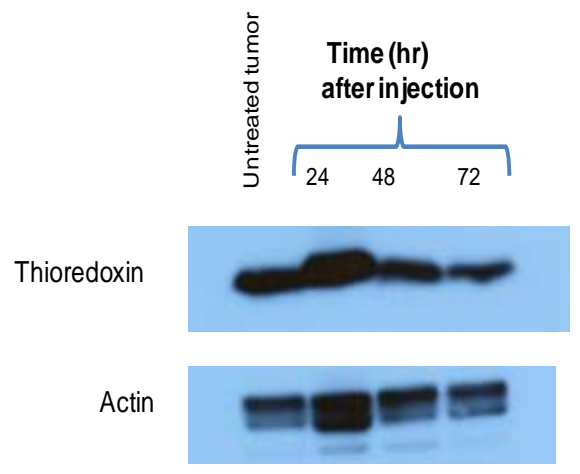

(b)

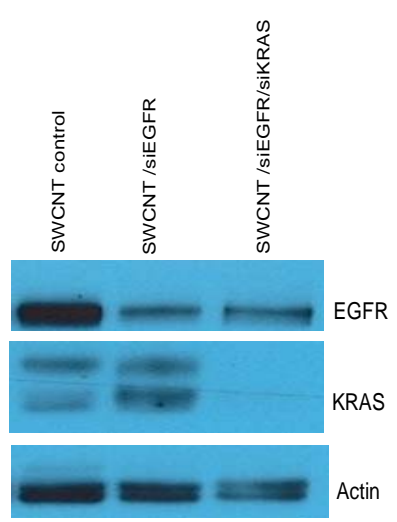

(c)

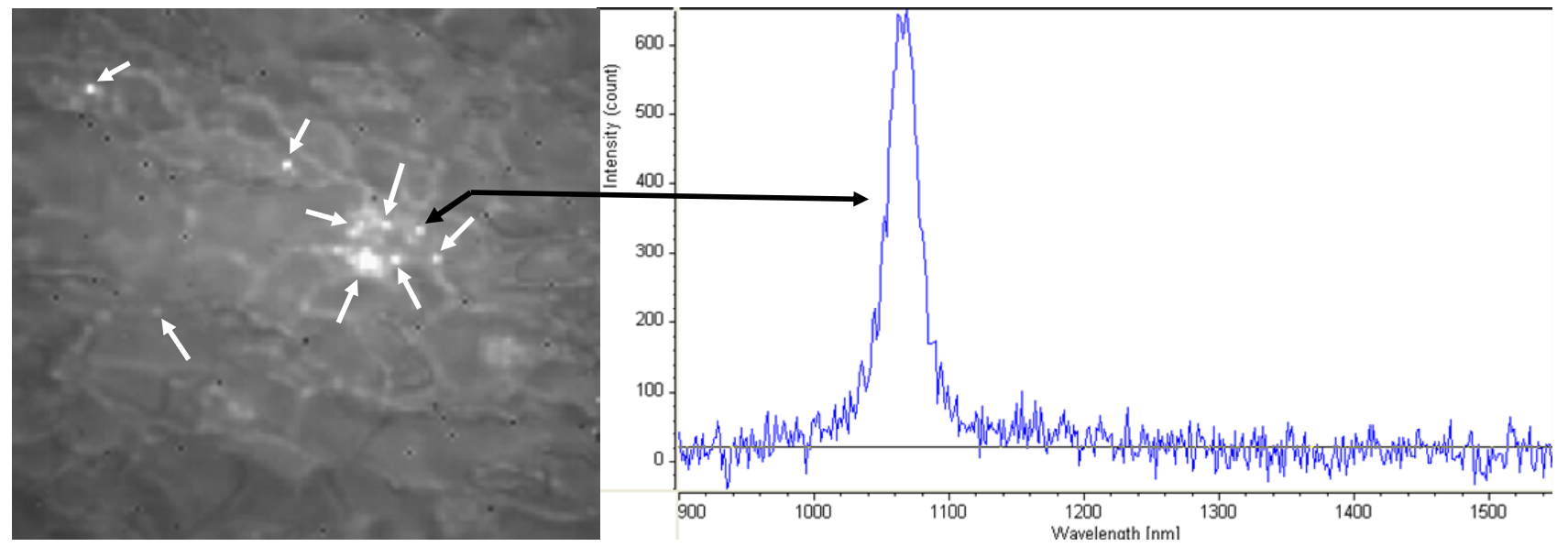

(d) 
Additionally the antitumor activity of the siRNA/SWCNT complexes has been demonstrated (Figure 8a,b) with no apparent toxicity from SWCNT in animal models bearing human tumor xenografts (Figure 8c,d). Groups of mice received siEGFR/SWCNT, siKRAS/SWCNT or the dual payload siEGFR/siKRAS/SWCNT by i.v. administration weekly or biweekly for 4 weeks. There was a trend for reduced tumor growth rate when mice were treated weekly, but there was significant growth delay observed when they were treated with the same preparations on a biweekly schedule. Hematology and blood chemistry revealed no toxicity $24 \mathrm{~h}$ following the last i.v. injection on week 4 (Figure $8 \mathrm{c}$ ) or at any time up to $96 \mathrm{~h}$ pi (data not shown). No weight loss was observed in any of the treatment groups whether treated weekly or biweekly (not shown).

Figure 8. In vivo antitumor activity is robust with biweekly administration. Mice ( 8 or $\mathrm{n}$ ) bearing MiaPaCa-2 human pancreatic tumors were treated with $35 \mu \mathrm{g}$ siRNA/PEG $8 \mu \mathrm{M} / \mathrm{SWCNT}$ complexes delivering $\sim 0.8 \mathrm{mg} / \mathrm{kg}$ siRNAs targeting EGFR, KRAS or both via tail vein injection. (a) Weekly for 4 weeks: *Days 15 to 23, significant difference in mean tumor growth rate siKRAS/SWCNT vs vehicle plus siRNA Control, $P=0.05$; (b) Biweekly for 4 weeks produced a significant difference for siKRAS-, siEGFR- and the dual siEGFR/siKRAS/SWCNT treated groups from vehicle siRNA control. The siRNA control (weekly) is shown with the biweekly data since only one animal was evaluable for the siRNA control (biweekly); (c) Hematology and blood chemistry showed no difference when performed $24 \mathrm{~h}$ after final injection following weekly administration for 4 weeks. Vehicle control was siRNA and PEG $8 \mu \mathrm{M}$ in $0.9 \%$ saline. ( $=$ normal mouse range). $\mathrm{NT}=$ non-treatment control; $\mathrm{S}=\mathrm{SWCNT}$ control; $\mathrm{E}=$ siEGFR/SWCNT; K = siKRAS/ SWCNT; E K = siEGFR/siKRAS/SWCNT. Subset of data is shown; (d) No weight loss was observed in animals treated weekly or biweekly (not shown).

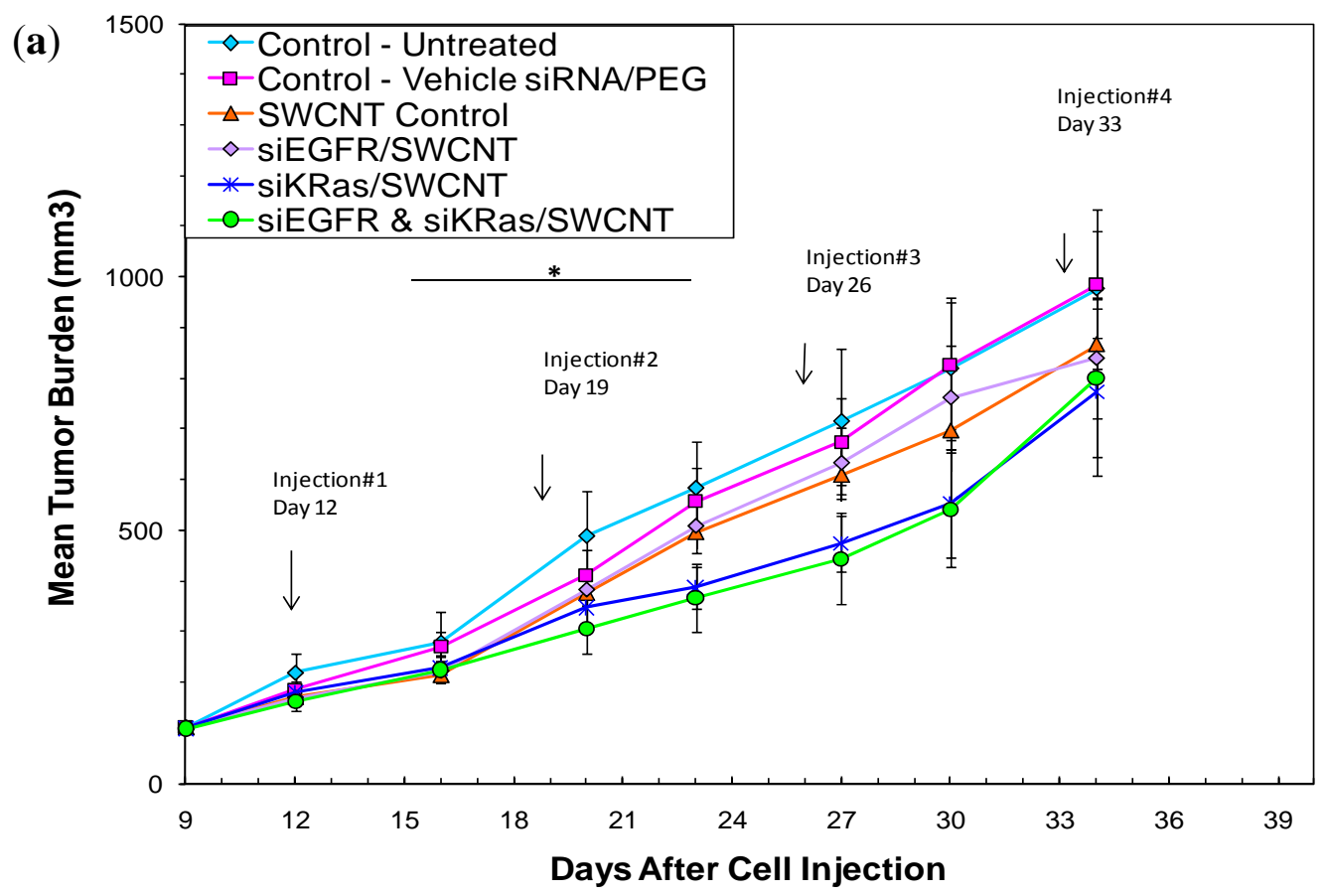


Figure 8. Cont.

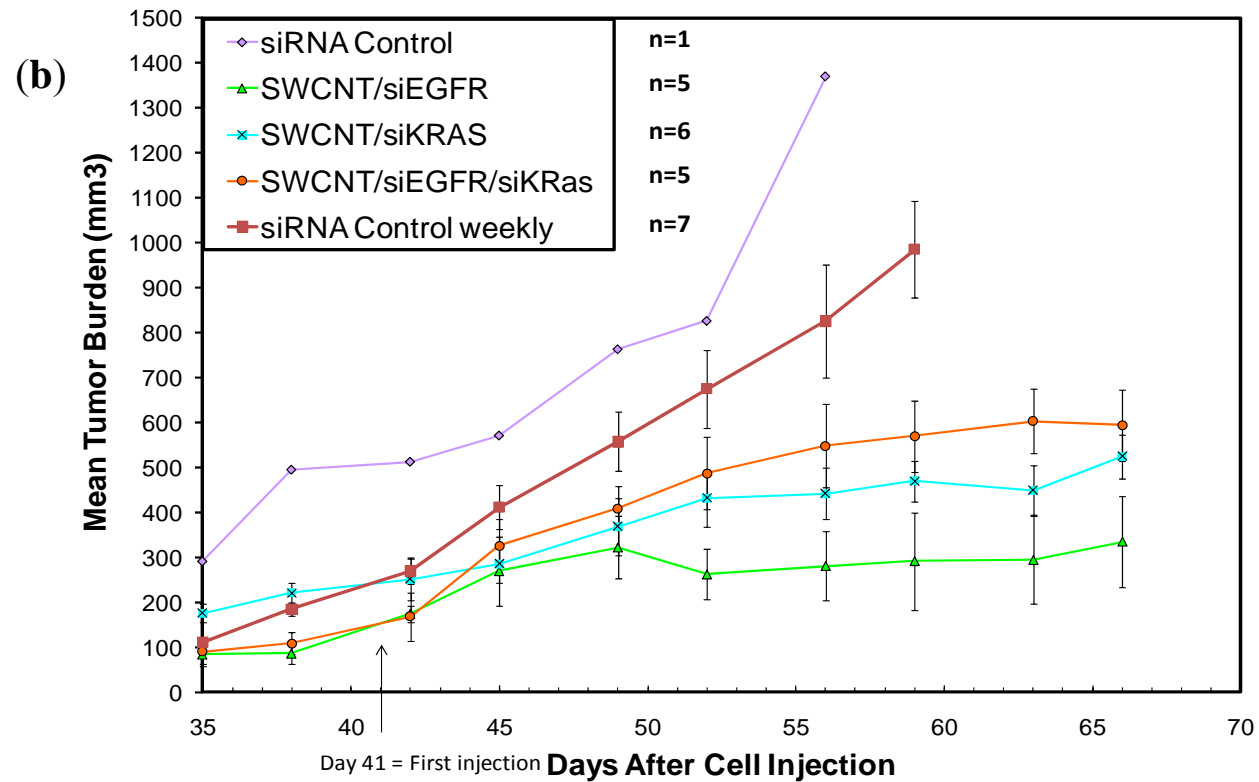

(c)

Mono \%

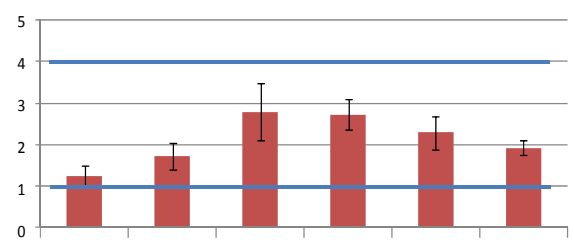

NT VC $S$ E $\quad$ K
Creatinine

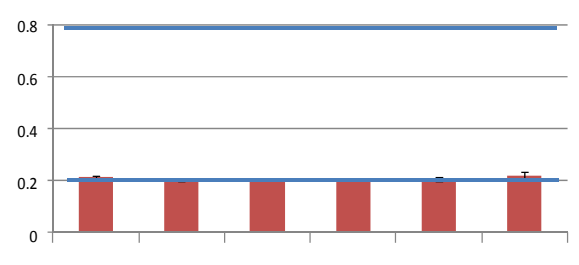

NT VC $S$ E $\quad K \quad E K$
ALT(SGPT)

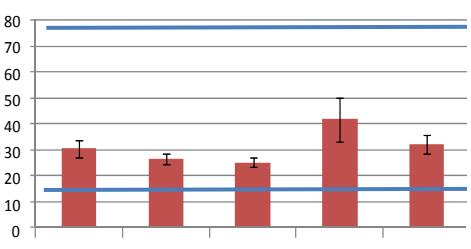

NT VC S E K
Lymph \%

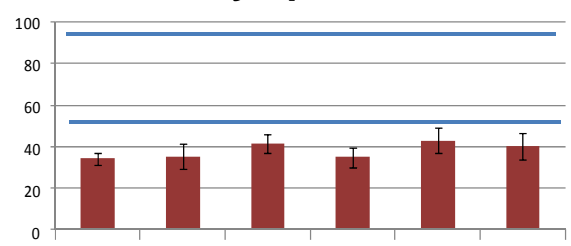

NT VC $S$ E $\quad K \quad E K$
BUN

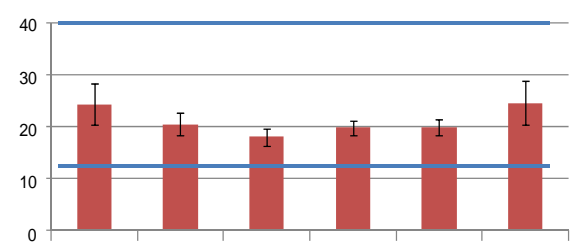

NT VC S E

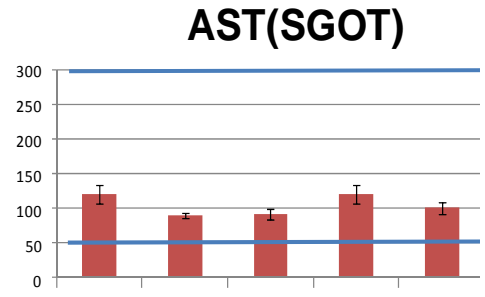

NT VC S E

(d)

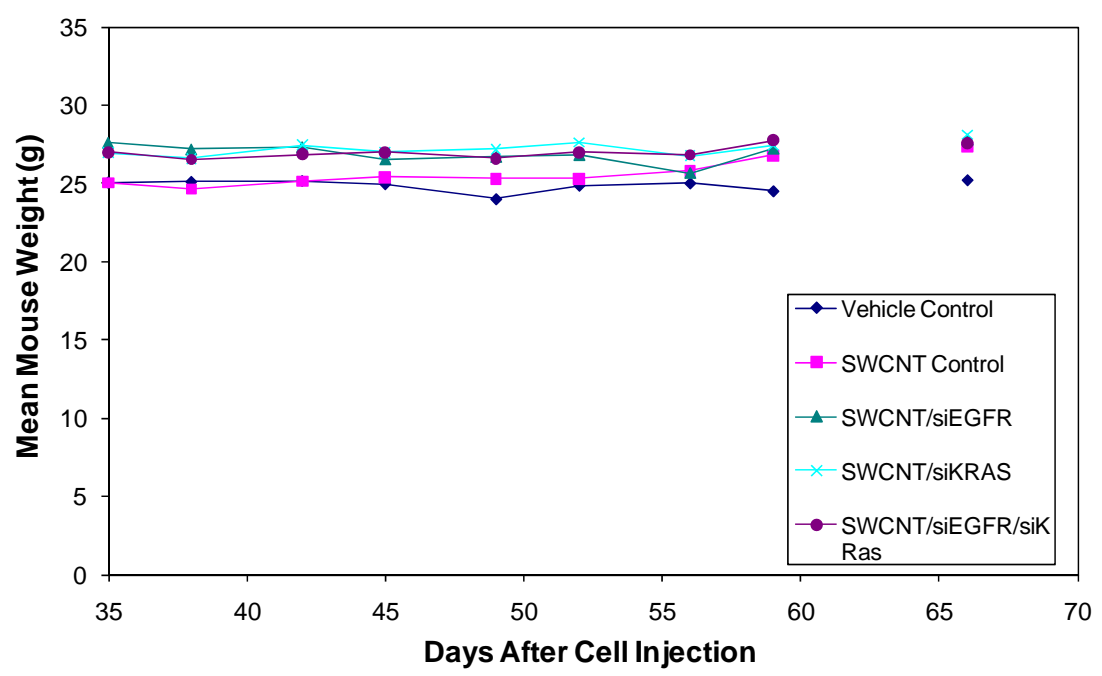




\subsection{Manipulating the Pharmacokinetic Properties of SWCNT}

Tumor localization for systemically delivered nanoparticles of siRNA relies mainly on the enhanced permeability and retention (EPR) effect and extravasation through leaky blood vessels in the tumor. However, most uptake of naked nanoparticles occurs by the RES of the liver and spleen, a process that is very rapid [54]. Attempts have been made to coat the nanoparticles with polyethyleneglycol or other materials to hide the particles from the RES ("stealth" nanoparticles), but with limited degrees of success. Attempts have also been made to prolong blood circulation time of the complexes as a more prolonged circulation of the nanoparticle is likely to favor accumulation in tumor by increasing the total number of passes made by the particle through the tumor vasculature [55]. We show that using PEG-lipid solutions in the formulation of the SWCNT complex can dramatically increase the SWCNT half-life in the plasma from minutes to $25 \mathrm{~h}$ (Figure 9) and increase tumor uptake. Importantly, others have shown that prolonging the plasma $t_{1 / 2}$ of the SWCNT nanoparticles can increase tumor versus liver and spleen uptake [56]. Finally, our data with administration of solubilized SWCNT or siRNA/SWCNT complex confirm accumulation in tumor, with steady clearance from tissues over time (Figure 10).

Figure 9. SWCNT complexed with siRNA and with excipients to modify the circulation time. (a) siRNA/l-PEG $(400 \mu \mathrm{M}) / \mathrm{SWCNT}, \mathrm{t}_{1 / 2}=8-10 \mathrm{~min}$; (b) siRNA/l-PEG $(1600 \mu \mathrm{M}) / \mathrm{SWCNT} ; \mathrm{t}_{1 / 2}=2.6 \mathrm{~h}$; (c) br-PEG/SWCNT: $\mathrm{t}_{1 / 2}=25 \mathrm{~h}$.

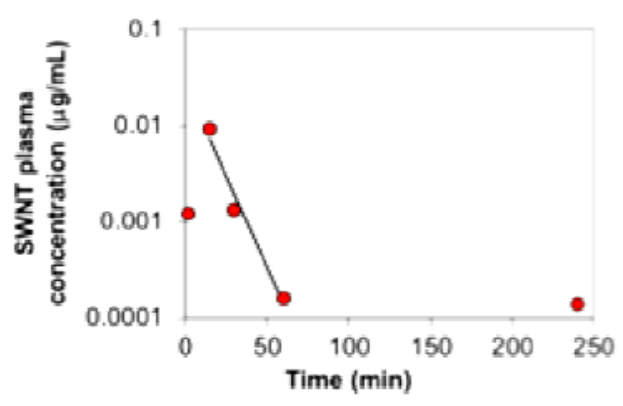

(a)

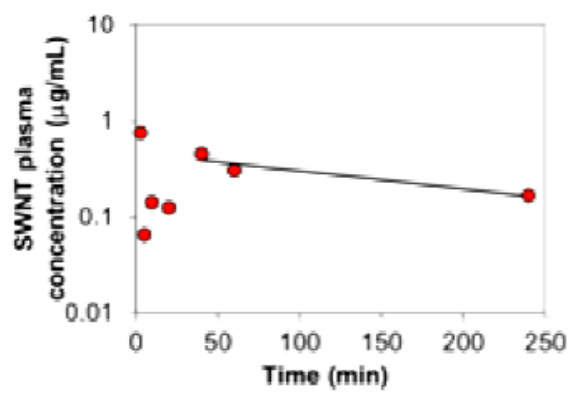

(b)

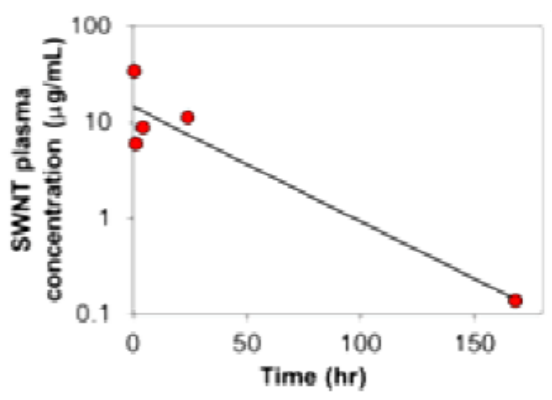

(c)

Figure 10. Relative SWCNT content in (a) spleen and (b) liver at 12, 24, $48 \mathrm{~h}$ and 1 week after mice received single bolus of $100 \mu \mathrm{g}$ SWCNT solubilized in $3 \%$ pluronic displayed by fluorescence spectra.

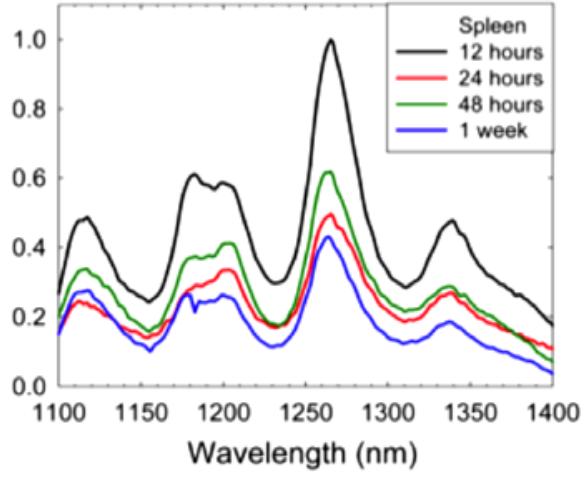

(a)

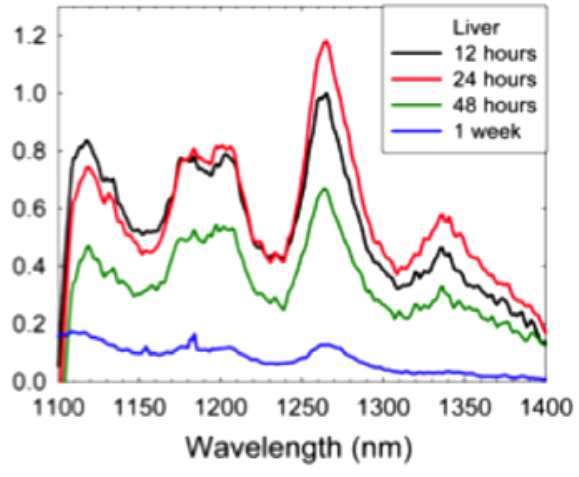

(b) 
The circulation time of siRNA/SWCNT complexes were measured and compared to samples with PEG added in the complexing procedure. Mice administered siRNA/SWCNT alone were administered $37 \mu \mathrm{g}$ SWCNT. Mice administered siRNA/PEG/SWCNT complexes received $100 \mu \mathrm{g}$ SWCNT. Figure 9 illustrates the plasma concentrations for siRNA/SWCNT complexes with l-PEG 400 and $1600 \mu \mathrm{M}$ and with $b r$-PEG $(1 \mathrm{mg} / \mathrm{mL}) / \mathrm{SWCNT}$ only in complexing mixture. With the injection of $100 \mu \mathrm{g}$ siRNA/SWCNT the SWCNT were detected in the circulation up to one $\mathrm{h}$ pi but $\mathrm{t}_{1 / 2}$ was minutes, while with the addition of $l$-PEG to the complex the $t_{1 / 2}$ could be increased based on the concentration of $l$-PEG used. $l$-PEG $(400 \mu \mathrm{M})$ increased circulation times up to 8-10 min while $l$-PEG $(1600 \mu \mathrm{M})$ increased the $t_{1 / 2}$ to $\sim 2.5 \mathrm{~h}$. Utilizing the same size of br-PEG complexed directly to SWCNT with no siRNA increased the $\mathrm{t}_{1 / 2}$ to $\sim 25 \mathrm{~h}$. We are continuing to explore the compositions to provide a complex with optimal $\mathrm{t}_{1 / 2}$ and biological activity.

Although $\mathrm{t}_{1 / 2}$ of siRNA/SWCNT or siRNA/l-PEG/SWCNT are relatively short, tissue levels can be measured especially in liver and spleen. With tumored mice there has been SWCNT also identified in the tumor and target KD has been determined (Figure 7). Tissue elimination has been measured and was found to occur over time. Solutions of SWCNT with no payload were used for this study using 3\% pluronic to solubilize. The $t_{1 / 2}$ of the solution was determined to be $8.2 \mathrm{~h}$. Figure 10 illustrates the fluorescent spectra of SWCNT from spleen and liver following a single $100 \mu \mathrm{g}$ i.v. dose over a period of 1 week, demonstrating that the SWCNT are steadily eliminated from tissue.

\section{Experimental Section}

\subsection{Preparation of SWCNT Solutions and SWCNT Complexes with siRNA}

SWCNT (HiPco, Rice University; Lot HPR 188.4) were suspended by ultrasonic agitation in solution of 3\% Pluronic ${ }^{\circledR}$ F-127: Sigma Aldrich (Saint Louis, MO) to form control solutions of SWCNT alone, or with siRNA in $0.9 \% \mathrm{NaCl}$ (siRNA targeting human EGFR (siEGFR): 5'-GAGGAAAUAUGUACUACGA[dT][dT]-3'; KRAS (siKRAS): 5'-GUCUCUUGGAUAUUCUCGA[dT][dT]-3' or thioredoxin-1 (siTrx) 5'-CUUGGACGCUGCAGGUGAU[dT][dT]-3' [Sigma Aldrich (Woodlands, TX, USA)] followed by centrifugation at $16,000 \times \mathrm{g}$ for $10 \mathrm{~min}$ at $4{ }^{\circ} \mathrm{C}$ to remove metal contaminants or bundled SWCNT. This yielded suspensions of SWCNT coated with pluronic or siRNA.

\section{2. siRNA/PEG/SWCNT Complex Preparation}

Raw HiPco SWCNT (4 mg) were added to $3.5 \mathrm{~mL}$ of siRNA $(571 \mu \mathrm{g} / \mathrm{mL})$ in $0.9 \% \mathrm{NaCl}$ (siKRAS, Sigma), sonicated (Covaris S2) at $10{ }^{\circ} \mathrm{C}$ for $2 \mathrm{~min}$ in $15 \mathrm{~s}$ pulses. PL-PEG: PL-PEG 5000: 14:0 PEG5000 PE (1,2-dimyristoyl-sn-glycero-3-phosphoethanolamine- $N$-[methoxy (polyethylene glycol)-5000]ammonium salt (Avanti Polar Lipids, Alabaster, AL, USA) (l-PEG) at 8, 200 or $1600 \mu \mathrm{M}$ in $0.9 \% \mathrm{NaCl}$ or branched PEG 5000 (br-PEG) [43] $200 \mu \mathrm{M}$ in $0.9 \% \mathrm{NaCl}$ was added and sonicated for another $4 \mathrm{~min}$ in $15 \mathrm{~s}$ pulses for a total of $6 \mathrm{~min}$. The samples were centrifuged at $16,000 \mathrm{~g}$ for $10 \mathrm{~min}$ at $4{ }^{\circ} \mathrm{C}$, the supernatant was transferred into a clean tube and centrifuged for another 10 mins. The resulting supernatant contained suspension of siRNA/PEG/SWCNT complex in concentrations ranging from 129 to $184 \mu \mathrm{g} / \mathrm{mL}$. The SWCNT concentration and degree of aggregation was determined by measuring absorbance at $632 \mathrm{~nm}$ and near-infrared fluorescence with 
NS2 NanoSpectralyzer (Applied NanoFluorescence). Excess siRNA and PEG were removed by filtration using 100-kDa filters (Vivaspin4, Sartorius) and washing three times with $0.9 \% \mathrm{NaCl}$ and the complex was resuspended in $0.9 \% \mathrm{NaCl}$ providing solutions to deliver up to $100 \mu \mathrm{g} / 250 \mu \mathrm{L}$. Size and length of complexes were analyzed by atomic force microscopy and dynamic light scattering.

For analyses of SWCNT length as a function of time, solutions of siRNA and SWCNT as above were sonicated in $15 \mathrm{~s}$ pulses for up to $12 \mathrm{~min}$. The samples were processed as described and the lengths were determined using AFM as described below.

\subsubsection{Atomic Force Microscopy (AFM)}

SWCNT length distributions in the samples of various compositions were assessed using AFM and compared to those measured by dynamic light scattering. Samples were prepared as described above and diluted to $\sim 2-5 \mu \mathrm{g} / \mathrm{mL}$ with $0.9 \% \mathrm{NaCl}$. They were deposited on the surface of $5 \times 5 \mathrm{~mm}$ silicon AFM substrates via spin-coating. The excess of surfactant (siRNA and PEG) on the substrate was washed off by an additional spin-coating of a drop of deionized water (DI) water. The optimal surface coverage for SWCNT length and height profile measurements was achieved at 20-50 SWCNT per $5 \times 5 \mu \mathrm{m}$ region. AFM imaging was performed using a Veeco Multimode IIIA AFM with TESPA AFM cantilever tips (Bruker Scientific). Regions of $5 \times 5 \mu \mathrm{m}$ were imaged for SWCNT length distribution measurements and $1 \times 1 \mu \mathrm{m}$ regions for height profile measurements. The lengths of more than 200 SWCNT were measured for each determination using Veeco NanoScope software length measuring tool.

\subsubsection{Dynamic Light Scattering (DLS) and Zeta Potential}

Samples were prepared as described above, diluted to 2,3 and $5 \mu \mathrm{g} / \mathrm{mL}$ with $0.9 \% \mathrm{NaCl}$ and transferred into plastic optical cuvettes. DLS and Zeta potential measurements were performed using Malvern Zen Zetasizer Nano. Hydrodynamic dimensions of SWCNT in suspension were determined by automatic software analysis of dynamic light scattering autocorrelation curves from 32 consecutive measurements. Up to five such measurement sets were averaged and the distribution of hydrodynamic dimensions was created for each sample. Zeta potentials were measured in Malvern Instruments Folded Capillary Cells with embedded electrodes. Each measurement consisted of up to 100 runs from which the average Zeta potential value was calculated. Suspension of polystyrene nanospheres (Malvern Instruments batch 261117) with specified zeta potential of $-68 \pm 6.8 \mathrm{mV}$ were routinely used as a standard for every set of measurements.

\subsection{In Vitro Stability of siRNA/SWCNT Complexes}

The concentration of each siRNA standard was determined by measuring UV absorbance at $260 \mathrm{~nm}$ and $280 \mathrm{~nm}$ using NanoDrop ${ }^{\mathrm{TM}} 1000$ spectrophotometer (Thermo Fisher Scientific). Stability of siRNA $(571 \mu \mathrm{g} / \mathrm{mL})$ in a solution of $64 \mu \mathrm{M}$ PEG in $0.9 \% \mathrm{NaCl}$ with or without complexation to SWCNT was evaluated in the presence of 10 units ribonuclease (RNAse $\mathrm{ONE}^{\mathrm{TM}}$ Ribonuclease, Promega, Madison, WI, USA) for 1,2 and $3 \mathrm{~h}$. After adding ribonuclease, the samples were pulse vortexed and pulse centrifuged to ensure adequate mixing, incubated at $37^{\circ} \mathrm{C}$ for up to three hours. Samples and standards 
(18 $\mu \mathrm{L}$ of 0 to $500 \mu \mathrm{g} / \mathrm{mL}$ siRNA) were mixed with $4 \mu \mathrm{L}$ 6X DNA loading dye (Fermentas R0611) and loaded on a 3\% agarose gel (Sigma Aldrich, St. Louis, MO, USA). Electrophoresis was performed at 100 $\mathrm{V}$ for $20 \mathrm{~min}$. The intensity of fluorescent signals from GelRed ${ }^{\mathrm{TM}}$ (ethidium bromide substitute, Phenix Research, Chandler, NC, USA) was quantified using a Carestream Health, Inc., Rochester, NY, USA. In Vivo MS FX PRO imaging system at 530/600 nm excitation/emission wavelengths.

\subsection{In Vitro Cellular Uptake Studies}

H2122 human non-small cell lung cancer (NSCLC) cells (ATCC, US) in culture were exposed to $1 \mu \mathrm{g} / \mathrm{mL}$ Cy-3-siTrx/SWCNT complex for 1 to $6 \mathrm{~h}$. Cells were washed and examined by bright field and fluorescence microscopy. NIR fluorescence was used to detect intracellular SWCNT and visible fluorescence to detect Cy-3-siRNA. NIR fluorescence microscopy was performed using a custom-built apparatus containing diode laser excitation sources emitting at 658 and $785 \mathrm{~nm}$ [57]. Cy-3 was excited with metal halide lamp and fluorescence was collected using a visible CCD camera (CoolSnap, Princeton Instruments) coupled to the microscope.

MiaCaPa-2 human pancreatic carcinoma cells were exposed to solutions of $0.2 \mu \mathrm{g} / \mathrm{mL}$ siRNA complexed to SWCNT or encapsulated in liposome (DharmaFECT2, Dharmacon Lafayette, CO, USA) and examined for SWCNT content via NIR fluorescence microscopy or Cy-3-siTrx via visible fluorescence as above.

\subsection{In Vivo Analyses of SWCNT and siRNA/SWCNT Complexes}

\subsubsection{Toxicity Evaluation of SWCNT with no siRNA Payload}

To solubilize SWCNT without siRNA an aqueous solution of pluronic F-127 was used to complex the nanotubes. Eight-week-old C57BL6 female mice (Harlan Laboratories, US) (six mice per group) were administered sufficient volume 3\% pluronic/SWCNT solution to deliver 50 and $100 \mu \mathrm{g}$ SWCNT or the equivalent volume of aqueous $3 \%$ pluronic (vehicle) via tail vein i.v. injections. Mice were sacrificed by $\mathrm{CO}_{2}$ euthanasia at $24 \mathrm{~h}$ and 1 week post injection. Blood was obtained by cardiac puncture, plasma prepared and stored frozen at $-80{ }^{\circ} \mathrm{C}$. Blood chemistries and hematology were analyzed for each group by MD Anderson Cancer Center, Department of Veterinary Medicine \& Surgery, Section of Laboratory Medicine. Tissues were harvested, flash frozen and stored at $-80{ }^{\circ} \mathrm{C}$ until processed to determine SWCNT concentration.

\subsubsection{Pharmacokinetic Analyses of siRNA/PEG/SWCNT Solutions}

siRNA/SWCNT solutions with or without PEG were administered to mice i.v. (100 $\mu \mathrm{g}$ SWCNT) into the tail vein. Mice were sacrificed by $\mathrm{CO}_{2}$ and blood was drawn by cardiac puncture at 3, 5, 10, 20, $60 \mathrm{~min}, 1,4$, and $24 \mathrm{~h}$ following injection. Blood samples were centrifuged at $1500 \mathrm{~g}$ for $15 \mathrm{~min}$ to separate optically transparent plasma from strongly absorbing red blood cells. Plasma (50 or $100 \mu \mathrm{L})$ was diluted in $300 \mu \mathrm{L}$ of $2 \%$ sodium deoxycholate and sonicated for $1 \mathrm{~s}$. Fluorescence signals were acquired at $637 \mathrm{~nm}$ laser excitation. A standard curve was generated using plasma samples, diluted with a series of $300 \mu \mathrm{L}$ of sodium deoxycholate-SWCNT suspension of a known concentration. The fluorescence spectra in PK samples comprised independent and distinct overlapping spectra of 
plasma autofluorescence and SWCNT fluorescence that were fit with linear combination of plasma background and SWCNT emission profile, measured independently. This methodology allows accurate measurements of SWCNT concentration of SWCNT with optical density as low as $10^{-5}$.

\subsubsection{Biodistribution and Elimination}

siTrx/l-PEG/SWCNT, l-PEG/SWCNT or $b r$-PEG/SWCNT solutions in $0.9 \% \mathrm{NaCl}$ were prepared to deliver $33 \mu \mathrm{g}$ SWCNT to eight-week-old $\mathrm{Nu} / \mathrm{Nu}$ female mice via tail vein i.v. injections bearing MiaPaCa-2 tumors. Mice were sacrificed by $\mathrm{CO}_{2}$ euthanasia at 24, 48, 72 and $96 \mathrm{~h}$ pi. Tissue and tumors were excised, half homogenized for Western blotting and half formalin-fixed, paraffin-embedded and sectioned in $4 \mu \mathrm{m}$ widths for SWCNT biodistribution analyses with NIR fluorescence microscopy.

To study elimination, 3\% pluronic/SWCNT solution to deliver 50 and $100 \mu \mathrm{g}$ SWCNT or the equivalent volume of aqueous 3\% pluronic (vehicle) were administered to eight-week-old $\mathrm{Nu} / \mathrm{Nu}$ female mice via tail vein i.v. injections. Mice were sacrificed by $\mathrm{CO}_{2}$ euthanasia at $5 \mathrm{~min}, 1,6$ and $24 \mathrm{~h}$ and 1 week post injection. Tissues were collected and flash frozen for future SWCNT analyses.

\subsection{Antitumor and Toxicity Evaluation of siEGFR/siKRAS/ SWCNT Payloads}

\subsubsection{Preparation of siEGFR/SWCNT or siKRAS/SWCNT and siEGFR/siKRAS/SWCNT}

Raw HiPco SWCNT (Lot HPR 188.4), approximately $4.0 \mathrm{mg}$, were dispersed in siRNA solutions of either siEGFR or siKRAS $(571.43 \mu \mathrm{g} / \mathrm{mL})$ or both $(1142.86 \mu \mathrm{g} / \mathrm{mL})$ and these mixtures were sonicated and prepared as described above with PL-PEG at $8 \mu \mathrm{M}$. The SWCNT control was prepared by bath sonicating $4 \mathrm{mg}$ of raw HiPco SWCNT in $4 \mathrm{~mL}$ of $2 \%$ pluronic (F127) for $1.5 \mathrm{~h}$ and then tip sonicating for $2 \mathrm{~min}$ in $15 \mathrm{~s}$ bursts. Supernatant containing SWCNT solutions was removed and transferred to a sterile $15 \mathrm{~mL}$ conical tube and stored refrigerated at $4{ }^{\circ} \mathrm{C}$. A $200 \mu \mathrm{L}$ sample of each solution was analyzed using NS2 Nanaspectralyzer to determine SWCNT concentration. For i.v. administration, all solutions were bath sonicated for $1.5 \mathrm{~h}$ prior to filling 1cc syringe (Kendall Monoject, $1 \mathrm{cc} 28 \mathrm{G} \times 1 / 2$ Syringe). Solutions containing SWCNT were prepared to deliver $35 \mu \mathrm{g}$ SWCNT in volume not exceeding $300 \mu \mathrm{L}$ while vehicle control containing aqueous PL-PEG $(8 \mu \mathrm{M})$ and siRNA $(42.86 \mu \mathrm{M})$ targeting both EGFR and KRAS was administered in $200 \mu \mathrm{L}$ volumes.

\subsubsection{Animal Treatment Schedule, Blood Draws and Tissue Harvesting}

Eight-week-old athymic Nude-Foxn $1^{\text {nu }}$ female mice (Harlan Laboratories) were inoculated subcutaneously with MiaPaCa-2 human pancreatic carcinoma cells $1 \times 10^{7}$ in $0.1 \mathrm{~mL}$ in the right flank. Animal weight and tumor volume was measured twice weekly and tumor volumes estimated using two diameters at right angles, measured with digital calipers; Tumor volume $\left(\mathrm{mm}^{3}\right)=$ diameter $_{\text {long }} \times$ diameter $_{\text {short }}^{2} \times 0.5$.

When tumors reached $100 \mathrm{~mm}^{3}$ they were randomized into groups of 10 and administered test solutions to deliver $35 \mu \mathrm{g}$ SWCNT per dose as per study arms below, through tail vein i.v. injections once or twice per week for a total of 4 weeks. After the last injection animals (2 per group) were sacrificed by $\mathrm{CO}_{2}$ euthanasia at 24, 48, 72, $96 \mathrm{~h}$ post injection. Blood samples were collected by 
cardiac puncture and tissues including tumor, liver, spleen, heart, kidneys, lungs, brain, muscle, bone were flash frozen for protein knockdown and SWCNT biodistribution analyses.

Hematology and blood chemistry analyses were conducted by MD Anderson Cancer Center, Department of Veterinary Medicine \& Surgery, Section of Laboratory Medicine for each group: Control-No treatment, Vehicle control, SWCNT Control, siEGFR/SWCNT, siKRAS/SWCNT, siEGFR/siKRAS/SWCNT at 24, 48, 72, 96 post final injections for 2 animals per study arm per time point.

\subsubsection{Tissue Analyses}

Western blotting: Tissues were homogenized using a Polytron PT 2100 drive unit and a 5-7.5 mm dispersing aggregate in $750-1500 \mu \mathrm{L}$ modified RIPA buffer $(150 \mathrm{mM} \mathrm{NaCl}, 1.0 \%$ Triton $\mathrm{X}-100,0.5 \%$ sodium deoxycholate, $0.1 \% \mathrm{SDS}, 50 \mathrm{mM}$ Tris $(\mathrm{pH} 8.0)$ containing $1 \%$ EDTA-free protease inhibitor cocktail (Thermo Scientific). After approximately 10-20 seconds of homogenization, lysates were obtained by centrifugation for $20 \mathrm{~min}$ at $17,800 \mathrm{~g}$ and $4{ }^{\circ} \mathrm{C}$. Lysates were stored at $-20{ }^{\circ} \mathrm{C}$ until analyzed. Aliquots containing $30 \mu \mathrm{g}$ protein were separated by SDS-PAGE using $12 \%$ Criterion XT Bis-Tris polyacrylamide gel (Bio-Rad, Hercules, CA), in MES/SDS Running buffer and transferred to a PVDF membrane. Western blotting was performed with specific primary antibodies against KRAS and EGFR and Actin (Santa Cruz Biotechnology, Santa Cruz, CA, USA) Membranes were exposed to anti-mouse (KRAS), anti-rabbit (EGFR) and anti-goat (Actin) HRP-conjugated-secondary antibodies in a $5 \%$ NFDM/TBS-T solution. Antibody-antigen complexes were visualized with HRP substrate chemiluminescent detection system (Perkin Elmer, Waltham, MA, USA).

Spectroscopy for determination of SWCNT concentration: Tissue $(0.5 \mathrm{~g})$ was placed in $1.5 \mathrm{~mL}$ of $4 \% \mathrm{NaDOC}$ solution and homogenized for $\sim 1$ min using homogenizer (Polytron, Kinematica) until homogeneous. Tissue homogenate, $0.5 \mathrm{~mL}$ was diluted 1:2 with $4 \% \mathrm{NaDOC}$ and sonicated (S2, Covaris) at $10{ }^{\circ} \mathrm{C}$ for $30 \mathrm{~min}$ using $15 \mathrm{~s}$ pulses in $1 \mathrm{~mL}$ glass tube. The resulting sample was used for SWCNT concentration analysis using NS2 NanoSpectralyzer (Applied NanoFluorescence). Fluorescence signals were acquired using $637 \mathrm{~nm}$ laser excitation.

Fluorescence microscopy of tumor tissues: Tumor tissue slices 24, 48, 72 and $96 \mathrm{~h}$ post injection were analyzed using custom-built NIR fluorescence microscopy setup mentioned above. Diode lasers (758 and $659 \mathrm{~nm}$ ) were used to excite SWCNT in tissue. Their NIR fluorescence was then collected by a $60 \times$ oil immersion objective and imaged with InGaAs $2 \mathrm{D}$ array camera. In order to distinguish SWCNT signal from occasional tissue fluorescence, spectra of bright fluorescing spots were recorded with InGaAs spectrograph. The ones representing a single Lorentzian were considered as individual SWCNT.

\section{Conclusions}

In summary, our biological data has demonstrated that there is no sequence dependency for the siRNA-SWCNT complex formation, and that SWCNT protect siRNA from enzymatic degradation when complexed. There is also no apparent cell line dependency for transfection, cellular uptake in vitro occurs rapidly and uniformly and the siRNA appears to be released from the SWCNT intracellularly. There is concentration and time dependent KD of target proteins. Multiple siRNA payloads can be delivered in one sample preparation and the complexes can be delivered systemically 
to produce target $\mathrm{KD}$ in tumors in vivo. Importantly, antitumor activity has been demonstrated accompanied by target KD with single and dual siRNA payloads, and the pharmacokinetic half-life can be altered by modifying payload composition. Finally, the complexes are well tolerated even with multi-day dosing for a 4 weeks period with no apparent toxicity from SWCNT in animal models bearing human tumor xenografts. Work is continuing to optimize the complex preparation and future studies will evaluate the antitumor activity of the optimized payloads.

\section{Acknowledgments}

This work has been in part supported through funding by the Emerging Technology Fund from the State of Texas. Special thanks to Sergi M. Bachilo who assisted with the HyperChem modeling of SWCNT complexes.

\section{References}

1. Liu, Z.; Chen, K.; Davis, C.; Sherlock, S.; Cao, Q.; Chen, X.; Dai, H. Drug delivery with carbon nanotubes for in vivo cancer treatment. Cancer Res. 2008, 68, 6652-6660.

2. Liu, Z.; Tabakman, S.; Welsher, K.; Dai, H. Carbon nanotubes in biology and medicine: In vitro and in vivo detection, imaging and drug delivery. Nano Res. 2009, 2, 85-120.

3. Liu, Z.; Fan, A.C.; Rakhra, K.; Sherlock, S.; Goodwin, A.; Chen, X.; Yang, Q.; Felsher, D.W.; Dai, H. Supramolecular stacking of doxorubicin on carbon nanotubes for in vivo cancer therapy. Angew. Chem. Int. Ed. Engl. 2009, 48, 7668-7672.

4. Kostarelos, K.; Bianco, A.; Prato, M. Promises, facts and challenges for carbon nanotubes in imaging and therapeutics. Nat. Nanotechnol. 2009, 4, 627-633.

5. Ruggiero, A.; Villa, C.H.; Holland, J.P.; Sprinkle, S.R.; May, C.; Lewis, J.S.; Scheinberg, D.A.; McDevitt, M.R. Imaging and treating tumor vasculature with targeted radiolabeled carbon nanotubes. Int. J. Nanomedicine 2010, 5, 783-802.

6. Han, Z.J.; Ostrikov, K.K.; Tan, C.M.; Tay, B.K.; Peel, S.A. Effect of hydrophilicity of carbon nanotube arrays on the release rate and activity of recombinant human bone morphogenetic protein-2. Nanotechnology 2011, 22, doi:10.1088/0957-4484/22/29/295712.

7. Beg, S.; Rizwan, M.; Sheikh, A.M.; Hasnain, M.S.; Anwer, K.; Kohli, K. Advancement in carbon nanotubes: Basics, biomedical applications and toxicity. J. Pharm. Pharmacol. 2011, 63, 141-163.

8. Pantarotto, D.; Singh, R.; McCarthy, D.; Erhardt, M.; Briand, J.P.; Prato, M.; Kostarelos, K.; Bianco, A. Functionalized carbon nanotubes for plasmid DNA gene delivery. Angew. Chem. Int. Ed. Engl. 2004, 43, 5242-5246.

9. Bartholomeusz, G.; Cherukuri, P.; Kingston, J.; Cognet, L.; Lemos, R.; Leeuw, T.K.; Gumbiner-Russo, L.; Weisman, R.B.; Powis, G. In vivo therapeutic silencing of hypoxia-inducible factor $1 \alpha(\mathrm{HIF}-1 \alpha)$ Using single-walled carbon nanotubes noncovalently coated with siRNA. Nano Res. 2009, 2, 279-291.

10. Pastorin, G. Crucial functionalizations of carbon nanotubes for improved drug delivery: A valuable option? Pharm. Res. 2009, 26, 746-769.

11. Ke, P.C. Carbon nanomaterials in biological systems. J. Phys. Condens. Matter 2007, 19, doi:10.1088/0953-8984/19/37/373101. 
12. Yang, R.; Yang, X.; Zhang, Z.; Zhang, Y.; Wang, S.; Cai, Z.; Jia, Y.; Ma, Y.; Zheng, C.; Lu, Y.; Roden, R.; Chen, Y. Single-walled carbon nanotubes-mediated in vivo and in vitro delivery of siRNA into antigen-presenting cells. Gene Ther. 2006, 13, 1714-1723.

13. Kam, N.W.; Liu, Z.; Dai, H. Functionalization of carbon nanotubes via cleavable disulfide bonds for efficient intracellular delivery of siRNA and potent gene silencing. J. Am. Chem. Soc. 2005, $127,12492-12493$.

14. Liu, Z.; Winters, M.; Holodniy, M.; Dai, H. siRNA delivery into human T cells and primary cells with carbon-nanotube transporters. Angew. Chem. Int. Ed. Engl. 2007, 46, 2023-2027.

15. Podesta, J.E.; Al-Jamal, K.T.; Herrero, M.A.; Tian, B.; Ali-Boucetta, H.; Hegde, V.; Bianco, A.; Prato, M.; Kostarelos, K. Antitumor activity and prolonged survival by carbon-nanotube-mediated therapeutic siRNA silencing in a human lung xenograft model. Small 2009, 5, 1176-1185.

16. Al-Jamal, K.T.; Gherardini, L.; Bardi, G.; Nunes, A.; Guo, C.; Bussy, C.; Herrero, M.A.; Bianco, A.; Prato, M.; Kostarelos, K.; et al. Functional motor recovery from brain ischemic insult by carbon nanotube-mediated siRNA silencing. Proc. Natl. Acad. Sci. USA 2011, 108, 10952-109527.

17. Bhirde, A.A.; Patel, V.; Gavard, J.; Zhang, G.; Sousa, A.A.; Masedunskas, A.; Leapman, R.D.; Weigert, R.; Gutkind, J.S.; Rusling, J.F. Targeted killing of cancer cells in vivo and in vitro with EGF-directed carbon nanotube-based drug delivery. ACS Nano 2009, 3, 307-316.

18. Ji, Z.; Lin, G.; Lu, Q.; Meng, L.; Shen, X.; Dong, L.; Fu, C.; Zhang, X. Targeted therapy of SMMC-7721 liver cancer in vitro and in vivo with carbon nanotubes based drug delivery system. J. Colloid. Interface Sci. 2012, 365, 143-149.

19. Guven, A.; Rusakova, I.A.; Lewis, M.T.; Wilson, L.J. Cisplatin@US-tube carbon nanocapsules for enhanced chemotherapeutic delivery. Biomaterials 2012, 33, 1455-1461.

20. Wu, Y.; Phillips, J.A.; Liu, H.; Yang, R.; Tan, W. Carbon nanotubes protect DNA strands during cellular delivery. ACS Nano 2008, 2, 2023-2028.

21. Welsher, K.; Liu, Z.; Sherlock, S.P.; Robinson, J.T.; Chen, Z.; Daranciang, D.; Dai, H. A route to brightly fluorescent carbon nanotubes for near-infrared imaging in mice. Nat. Nanotechnol. 2009, 4, 773-780.

22. Welsher, K.; Sherlock, S.P.; Dai, H. Deep-tissue anatomical imaging of mice using carbon nanotube fluorophores in the second near-infrared window. Proc. Natl. Acad. Sci. USA 2011, 108, 8943-8948.

23. Peng, G.; Tisch, U.; Haick, H. Detection of nonpolar molecules by means of carrier scattering in random networks of carbon nanotubes: Toward diagnosis of diseases via breath samples. Nano Lett. 2009, 9, 1362-1368.

24. Jin, H.; Heller, D.A.; Kalbacova, M.; Kim, J.H.; Zhang, J.; Boghossian, A.A.; Maheshri, N.; Strano, M.S. Detection of single-molecule H2O2 signalling from epidermal growth factor receptor using fluorescent single-walled carbon nanotubes. Nat. Nanotechnol. 2010, 5, 302-309.

25. Heller, D.A.; Jin, H.; Martinez, B.M.; Patel, D.; Miller, B.M.; Yeung, T.K.; Jena, P.V.; Hobartner, C.; Ha, T.; Silverman, S.K.; et al. Multimodal optical sensing and analyte specificity using single-walled carbon nanotubes. Nat. Nanotechnol. 2009, 4, 114-120.

26. Barone, P.W.; Strano, M.S. Reversible control of carbon nanotube aggregation for a glucose affinity sensor. Angew. Chem. Int. Ed. Engl. 2006, 45, 8138-8141. 
27. Lin, Y.; Lu, F.; Tu, Y.; Ren, Z. Glucose biosensors based on carbon nanotube nanoelectrode ensembles. Nano Lett. 2004, 4, 191-195.

28. Ghosh, S.; Dutta, S.; Gomes, E.; Carroll, D.; D’Agostino, R., Jr.; Olson, J.; Guthold, M.; Gmeiner, W.H. Increased heating efficiency and selective thermal ablation of malignant tissue with DNA-encased multiwalled carbon nanotubes. ACS Nano 2009, 3, 2667-2673.

29. Zhou, F.; Xing, D.; Ou, Z.; Wu, B.; Resasco, D.E.; Chen, W.R. Cancer photothermal therapy in the near-infrared region by using single-walled carbon nanotubes. J. Biomed. Opt. 2009, 14, doi:10.1117/1.3078803.

30. Robinson, J.T.; Welsher, K.; Tabakman, S.M.; Sherlock, S.P.; Wang, H.; Luong, R.; Dai, H. High performance In vivo near-IR ( $>1$ mum) imaging and photothermal cancer therapy with carbon nanotubes. Nano Res. 2010, 3, 779-793.

31. Tasis, D.; Tagmatarchis, N.; Georgakilas, V.; Prato, M. Soluble carbon nanotubes. Chemistry 2003, 9, 4000-4008.

32. Maynard, A.D.; Baron, P.A.; Foley, M.; Shvedova, A.A.; Kisin, E.R.; Castranova, V. Exposure to carbon nanotube material: Aerosol release during the handling of unrefined single-walled carbon nanotube material. J. Toxicol. Environ. Health. A 2004, 67, 87-107.

33. Huczko, A.; Lange, H.; Bystrzejewski, M.; Baranowski, P.; Grubek-Jaworska, H.; Nejman, P.; Przybylowski, T.; Czuminska, K.; Glapinski, J.; Walton, D.R.M.; et al. Pulmonary toxicity of 1-D nanocarbon materials. Fuller. Nanotub. Carbon Nanostructures 2005, 13, 141-145.

34. Lam, C.W.; James, J.T.; McCluskey, R.; Hunter, R.L. Pulmonary toxicity of single-wall carbon nanotubes in mice 7 and 90 days after intratracheal instillation. Toxicol. Sci. 2004, 77, 126-134.

35. Warheit, D.B.; Laurence, B.R.; Reed, K.L.; Roach, D.H.; Reynolds, G.A.; Webb, T.R. Comparative pulmonary toxicity assessment of single-wall carbon nanotubes in rats. Toxicol. Sci. 2004, 77, 117-125.

36. Shvedova, A.A.; Kisin, E.R.; Mercer, R.; Murray, A.R.; Johnson, V.J.; Potapovich, A.I.; Tyurina, Y.Y.; Gorelik, O.; Arepalli, S.; Schwegler-Berry, D.; et al. Unusual inflammatory and fibrogenic pulmonary responses to single-walled carbon nanotubes in mice. Am. J. Physiol. Lung Cell Mol. Physiol. 2005, 289, L698-L708.

37. Huczko, A.; Lange, H. Carbon nanotubes: Experimental evidence for a null risk of skin irritation and allergy. Fuller. Sci. Technol. 2001, 9, 247-250.

38. Yokoyama, A.; Sato, Y.; Nodasaka, Y.; Yamamoto, S.; Kawasaki, T.; Shindoh, M.; Kohgo, T.; Akasaka, T.; Uo, M.; Watari, F.; et al. Biological behavior of hat-stacked carbon nanofibers in the subcutaneous tissue in rats. Nano Lett. 2005, 5, 157-161.

39. Sato, Y.; Yokoyama, A.; Shibata, K.; Akimoto, Y.; Ogino, S.; Nodasaka, Y.; Kohgo, T.; Tamura, K.; Akasaka, T.; Uo, M.; et al. Influence of length on cytotoxicity of multi-walled carbon nanotubes against human acute monocytic leukemia cell line THP-1 in vitro and subcutaneous tissue of rats in vivo. Mol. Biosyst. 2005, 1, 176-182.

40. Kostarelos, K. The long and short of carbon nanotube toxicity. Nat. Biotechnol. 2008, 26, 774-776.

41. Ruggiero, A.; Villa, C.H.; Bander, E.; Rey, D.A.; Bergkvist, M.; Batt, C.A.; Manova-Todorova, K.; Deen, W.M.; Scheinberg, D.A.; McDevitt, M.R. Paradoxical glomerular filtration of carbon nanotubes. Proc. Natl. Acad. Sci. USA 2010, 107, 12369-12374. 
42. Liu, Z.; Davis, C.; Cai, W.; He, L.; Chen, X.; Dai, H. Circulation and long-term fate of functionalized, biocompatible single-walled carbon nanotubes in mice probed by Raman spectroscopy. Proc. Natl. Acad. Sci. USA 2008, 105, 1410-1415.

43. Salvador-Morales, C.; Flahaut, E.; Sim, E.; Sloan, J.; Green, M.L.; Sim, R.B. Complement activation and protein adsorption by carbon nanotubes. Mol. Immunol. 2006, 43, 193-201.

44. Hamad, I.; Christy Hunter, A.; Rutt, K.J.; Liu, Z.; Dai, H.; Moein Moghimi, S. Complement activation by PEGylated single-walled carbon nanotubes is independent of $\mathrm{C} 1 \mathrm{q}$ and alternative pathway turnover. Mol. Immunol. 2008, 45, 3797-3803.

45. Lam, C.W.; James, J.T.; McCluskey, R.; Arepalli, S.; Hunter, R.L. A review of carbon nanotube toxicity and assessment of potential occupational and environmental health risks. Crit. Rev. Toxicol. 2006, 36, 189-217.

46. Sayes, C.M.; Liang, F.; Hudson, J.L.; Mendez, J.; Guo, W.; Beach, J.M.; Moore, V.C.; Doyle, C.D.; West, J.L.; Billups, W.E.; et al. Functionalization density dependence of single-walled carbon nanotubes cytotoxicity in vitro. Toxicol. Lett. 2006, 161, 135-142.

47. Lacerda, L.; Ali-Boucetta, H.; Herrero, M.A.; Pastorin, G.; Bianco, A.; Prato, M.; Kostarelos, K. Tissue histology and physiology following intravenous administration of different types of functionalized multiwalled carbon nanotubes. Nanomedicine 2008, 3, 149-161.

48. Singh, R.; Pantarotto, D.; Lacerda, L.; Pastorin, G.; Klumpp, C.; Prato, M.; Bianco, A.; Kostarelos, K. Tissue biodistribution and blood clearance rates of intravenously administered carbon nanotube radiotracers. Proc. Natl. Acad. Sci. USA 2006, 103, 3357-3362.

49. Schipper, M.L.; Nakayama-Ratchford, N.; Davis, C.R.; Kam, N.W.; Chu, P.; Liu, Z.; Sun, X.; Dai, H.; Gambhir, S.S. A pilot toxicology study of single-walled carbon nanotubes in a small sample of mice. Nat. Nanotechnol. 2008, 3, 216-221.

50. Cherukuri, P.; Gannon, C.J.; Leeuw, T.K.; Schmidt, H.K.; Smalley, R.E.; Curley, S.A.; Weisman, R.B. Mammalian pharmacokinetics of carbon nanotubes using intrinsic near-infrared fluorescence. Proc. Natl. Acad. Sci. USA 2006, 103, 18882-18886.

51. Yang, S.-T.; Guo, W.; Lin, Y.; Deng, X.-Y.; Wang, H.-F.; Sun, H.-F.; Liu, Y.-F.; Wang, X.; Wang, W.; Chen, M.; et al. Biodistribution of pristine single-walled carbon nanotubes in vivo. J. Phys. Chem. C 2007, 111, 17761-17764.

52. Cai, D.; Kempa, K.; Ren, Z.; Carnahan, D.; Chiles, T.C. Nanospearing-Biomolecule delivery and its biocompatibility. Nanomater. Appl. Med. Biol. 2008, 81-92.

53. Zhang, X.; Meng, L.; Wang, X.; Lu, Q. Preparation and cellular uptake of pH-dependent fluorescent single-wall carbon nanotubes. Chemistry 2010, 16, 556-561.

54. Gaur, U.; Sahoo, S.K.; De, T.K.; Ghosh, P.C.; Maitra, A.; Ghosh, P.K. Biodistribution of fluoresceinated dextran using novel nanoparticles evading reticuloendothelial system. Int. J. Pharm. 2000, 202, 1-10.

55. Harrington, K.J.; Mohammadtaghi, S.; Uster, P.S.; Glass, D.; Peters, A.M.; Vile, R.G.; Stewart, J.S. Effective targeting of solid tumors in patients with locally advanced cancers by radiolabeled pegylated liposomes. Clin. Cancer. Res. 2001, 7, 243-254.

56. Liu, X.; Tao, H.; Yang, K.; Zhang, S.; Lee, S.T.; Liu, Z. Optimization of surface chemistry on single-walled carbon nanotubes for in vivo photothermal ablation of tumors. Biomaterials 2011, 32, 144-151. 
57. Tsyboulski, D.A.; Bachilo, S.M.; Weisman, R.B. Versatile visualization of individual single-walled carbon nanotubes with near-infrared fluorescence microscopy. Nano Lett. 2005, 5, 975-979.

(C) 2012 by the authors; licensee MDPI, Basel, Switzerland. This article is an open access article distributed under the terms and conditions of the Creative Commons Attribution license (http://creativecommons.org/licenses/by/3.0/). 